\title{
Subseasonal Forecasting with an Icosahedral, Vertically Quasi-Lagrangian Coupled Model. Part II: Probabilistic and Deterministic Forecast Skill
}

\author{
SHAN Sun AND BENJAMIN W. GREEN \\ Cooperative Institute for Research in Environmental Sciences, University of Colorado Boulder, \\ and NOAA/OAR/ESRL/Global Systems Division, Boulder, Colorado \\ RAINER BLECK \\ Cooperative Institute for Research in Environmental Sciences, University of Colorado Boulder, \\ and NOAA/OAR/ESRL/Global Systems Division, Boulder, Colorado, and \\ NASA Goddard Institute for Space Studies, New York, New York \\ STANLEY G. BENJAMIN \\ NOAA/OAR/ESRL/Global Systems Division, Boulder, Colorado
}

(Manuscript received 9 January 2018, in final form 3 April 2018)

\begin{abstract}
Subseasonal forecast skill of the global hydrostatic atmospheric Flow-Following Icosahedral Model (FIM) coupled to an icosahedral-grid version of the Hybrid Coordinate Ocean Model (iHYCOM) is evaluated through 32-day predictions initialized weekly using a four-member time-lagged ensemble over the 16-yr period 19992014. Systematic biases in forecasts by the coupled system, referred to as FIM-iHYCOM, are described in a companion paper (Part I). This present study (Part II) assesses probabilistic and deterministic model skill for predictions of surface temperature, precipitation, and 500-hPa geopotential height in different seasons at different lead times ranging from 1 to 4 weeks. The coupled model appears to have reasonable agreement with reanalysis in terms of simulated weekly variability in sea surface temperatures, except in extratropical regions because the ocean model cannot explicitly resolve eddies there. This study also describes the ability of the model to simulate midlatitude tropospheric blocking frequency, Madden-Julian oscillation patterns, and sudden stratospheric warming events-all of which have been shown to be relevant on subseasonal time scales. The metrics used here indicate that the subseasonal forecast skill of the model is comparable to that of several operational models, including the National Oceanic and Atmospheric Administration's (NOAA's) operational Climate Forecast System version 2 and the European Centre for Medium-Range Weather Forecasts model. Therefore, FIM-iHYCOM - as a participant in NOAA's Subseasonal Experiment-is expected to add value to multimodel ensemble forecasts produced through this effort.
\end{abstract}

\section{Introduction}

Considerable effort is presently invested in providing and improving subseasonal forecasts ( $\sim 2$ weeks to 2 months) because of the importance of this time scale in many sectors of society (Brunet et al. 2010; WMO 2015; NAS 2016). Several operational centers have been issuing subseasonalto-seasonal (S2S) forecasts for more than a decade (Vitart 2004; Saha et al. 2014; Kim et al. 2014; Lin et al. 2016; Wheeler et al. 2017). Although subseasonal time scales fall outside the theoretical deterministic predictability limit

\footnotetext{
Corresponding author: Shan Sun, shan.sun@noaa.gov
}

of $\sim 2$ weeks in the midlatitudes (Lorenz 1969), there is sufficient evidence that potential sources of subseasonal predictability are seen in relatively long-lived flow configurations in the tropics (Charney and Shukla 1981), such as the Madden-Julian oscillation (MJO; Waliser et al. 2003), and tropospheric blocking at midlatitudes (Matsueda 2011). Major changes in the wintertime upper-stratospheric circulation associated with sudden stratospheric warmings (SSWs) likewise are being investigated as potential precursors of persistent tropospheric circulation anomalies at high latitudes (Baldwin and Dunkerton 1999; Shaw and Perlwitz 2013). In addition, capitalizing on relatively slowvarying processes involving sea ice extent, soil moisture 
(Beljaars et al. 1996), snow cover (Walland and Simmonds 1996), and the ocean state has the potential for improving S2S predictions. In particular, ocean heat content fluctuations, especially when associated with El Niño-Southern Oscillation (ENSO), have a long-lasting impact not only on the tropics, but globally due to atmospheric teleconnections (Hoerling and Kumar 2002).

Studies have also shown that ensemble-based probabilistic prediction on the S2S time scale can exhibit skill relative to forecasts based on persistence (e.g., Palmer 2002; Zhu et al. 2014; Smith et al. 2015; Lin et al. 2016). There has been widespread and still-increasing use of ensemble forecasting to improve forecast skill at all time scales. Two approaches for generating an ensemble prediction system based on dynamical forecast models have been used:

1) Use of a single model ensemble whose members are diversified by perturbed or lagged initial conditions. Some such systems also include stochastic perturbations of model physics (e.g., Kalnay and Dalcher 1987; Palmer and Tibaldi 1988; Straus and Shukla 2000; Vitart 2014).

2) Use of several models in a multimodel ensemble (e.g., Krishnamurti et al. 2003; Palmer et al. 2004; Kirtman et al. 2014; Li and Robertson 2015; Vigaud et al. 2017).

This pragmatic shift to probabilistic forecasting to reflect the inherently chaotic nature of atmospheric behavior has effectively improved skill in the subseasonalto-interannual prediction range. At these time scales, multimodel ensemble forecasts have been found to be better than those based on any one single model, as shown in, for example, the Development of a European Multimodel Ensemble System for Seasonal to Interannual Prediction (DEMETER; Palmer et al. 2004) and North American Multimodel Ensemble (NMME; Kirtman et al. 2014). Nevertheless, forecasts are still susceptible to errors from deficiencies in the treatment of spatially unresolved physical processes and finite-difference approximations in the model equations. To maximize the gain from ensemble methods, approach 2 above requires that attention be paid to model diversity in order to assure sufficient spread among ensemble members and not just reduction in overall bias. This makes models with diverse subgrid-scale physical parameterizations and innovative numerics attractive in multimodel ensembles.

Nevertheless, continuing development of individual models still appears to offer the best chance for improving subseasonal prediction, mainly by improving representation of the Earth system processes listed above. The goals of this article are to evaluate the subseasonal forecast skill of a new coupled model-the atmospheric Flow-Following Icosahedral Model (FIM; Bleck et al. 2015) coupled to an icosahedral grid version of the Hybrid Coordinate Ocean Model (iHYCOM; cf. Bleck 2002)-in a multiyear set of 32-day hindcasts, with emphasis on seasonal and geographic skill variations. Given that the coupled model, referred to here as FIM-iHYCOM, has been described in detail in Sun et al. (2018, hereafter Part I), we concentrate in section 2 of the present article (Part II) on the details of the model climatology and bias removal. Weekly variability of sea surface temperature (SST) between reanalysis and FIM-iHYCOM is also compared. Skill measures in predicting a number of relevant variables and phenomena are presented in section 3 , followed by a discussion in section 4 .

\section{Model climatology and SST variability}

\section{a. Model climatology and bias removal}

As discussed in Part I, FIM-iHYCOM hindcasts were carried out over a 16-yr period initialized weekly with four time-lagged ensemble members for a total of 835 weeks, yielding 3340 simulations. The model output is interpolated onto a $1^{\circ} \times 1^{\circ}$ horizontal grid and averaged to either daily or weekly means for various lead times, depending on different applications shown later.

To increase the sample size for a model climatology, FIM-iHYCOM was also initialized daily at 0000 UTC from 1 January 1999 through 31 December 2014, ${ }^{1}$ a total of 5844 simulations. For the purpose of bias correction, at each latitude-longitude point and for each lead day independently, the resulting hindcasts were first averaged over the number of available years (i.e., 4 years for 29 February and 16 years for the remaining 365 days). This yielded averaged fields, henceforth referred to as "raw model climatology," with dimensions 366 (initialization days of the year) $\times 32$ (forecast lead days) $\times 181 \times 360$ (latitude-longitude points). Then, for each lead day at each latitude-longitude point, 10 passes of a 25-day low-pass numerical filter, described in the appendix, were applied across the 366-day dimension. The number of filter passes was chosen empirically to balance noise removal necessitated by limited sampling and retention of physical signals.

The resulting lead-dependent daily model climatology is used to perform bias correction before assessing skill in most of the results presented below, with the following exception: the results from probabilistic forecasts do

\footnotetext{
${ }^{1}$ Note that there is some overlap, namely, 0000 UTC every Wednesday, between this hindcast and the abovementioned fourmember time-lagged ensemble initialized weekly.
} 
not employ the bias correction method described above because, as noted in section $3 \mathrm{a}$, model bias is accounted for implicitly.

For the purpose of bias-correcting subseasonal forecasts from NOAA's Climate Forecast System (CFS) version 2 (CFSv2; Saha et al. 2014), climatologies for CFS Reanalysis (CFSR; Saha et al. 2010) and for leaddependent CFSv2, calculated following Zhang and van den Dool (2012), were downloaded from the National Centers for Environmental Information (NCEI). Note that CFS climatology is calculated over the period 19822010 due to data/computational constraints. It should be noted that Saha et al. (2014, p. 2199) recommend using a "split climatology" based upon data from 1999 onward for both precipitation and SST in the tropical Pacific; however, this is not a concern here because none of our precipitation results include data equatorward of $20^{\circ} \mathrm{N}$.

Figure 1 shows one example of how the low-pass filter (red curve) removes sampling noise from the raw FIM-iHYCOM model climatology (green curve) of 2-m temperature $(\mathrm{T} 2 \mathrm{~m})$ at a particular geographic location at a lead time of 1 day. These climatologies can also be compared with the corresponding CFSR climatology (black curve); this curve is noticeably smoother than the FIM-iHYCOM-filtered climatology. The difference between the red and black curves represents the bias correction that is applied to FIM-iHYCOM hindcasts.

\section{b. SST variability in FIM-iHYCOM}

Model overview articles, especially those dealing with subseasonal or longer time scales, often go beyond an assessment of systematic biases and examine the ability of the model to reproduce observed temporal variability (e.g., Pegion and Kirtman 2008; Saha et al. 2014). Typically, such variability analyses are from multiyear model integrations that are then filtered to isolate the desired time scale. Because such a long integration of FIM-iHYCOM does not yet exist, the previously described 16-yr hindcast dataset, along with the filtered model climatology, is used. To calculate variability in FIM-iHYCOM, the general approach of Saha et al. (2014; their Fig. 3) is followed: we compute anomalies with respect to model climatology and then compute the variability of these anomaly fields.

Because the focus of Part I and Part II is on subseasonal prediction, variability was computed from weekly data using the following procedure. First, the filtered leaddependent model climatology was removed from each of the four ensemble members to give daily model anomalies. Then, for each ensemble member separately, the daily anomalies were averaged over weeklong periods to obtain weekly model anomalies. Next, for a given target season [e.g., December-February (DJF); see Part I for

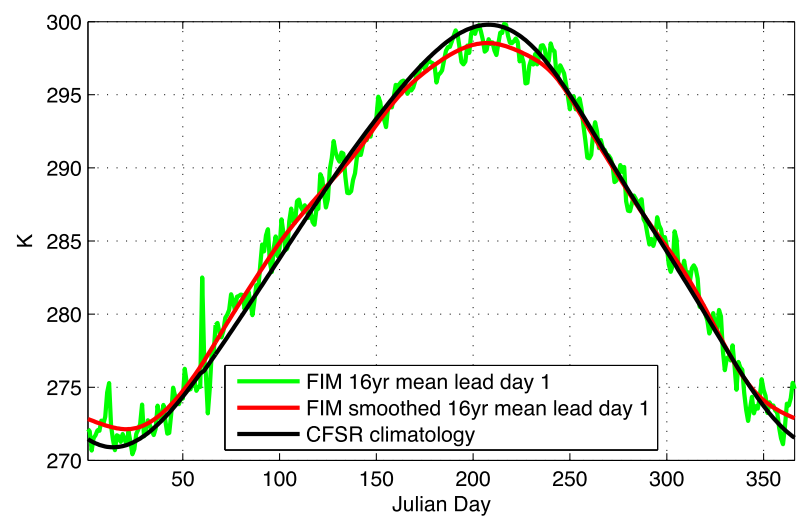

FIG. 1. T2m climatology at $40^{\circ} \mathrm{N}, 90^{\circ} \mathrm{W}$ for FIM-iHYCOM for day 1 lead time. Green curve: raw climatology (simple average over the 16-yr period); red curve: smoothed climatology after 10 passes of 25-day filter. CFSR climatology provided by NCEI is shown for comparison (black curve).

details on "target" season)] and a given forecast lead week (1-4) for each ensemble member separately, the variance of the weekly model anomalies was calculated. As an example for DJF, there are $\sim 12$ weeks per season and 14 DJF seasons, so $\sim 168$ cases for each lead week were included in the variance calculation of each of the four ensemble members. Finally, for plotting purposes, the mean of the four ensemble member variances was taken.

The resulting SST variances for FIM-iHYCOM were compared with SST variances from CFSR. The methodology to compute weekly variances from CFSR is similar to that described above, except that there are no ensembles and no dependence on forecast lead time. Instead, CFSR variances were simply computed based on the 1999-2014 period for those Wednesday-Tuesday weeks whose midweek day (Saturday) fell in the desired target season.

Figure 2 shows, for DJF, the CFSR weekly SST variance along with the difference in variance between FIM-iHYCOM ("FIMr1.1," as in Part I) and CFSR for forecast lead weeks 1-4. Looking at Fig. 2a and ignoring sea ice areas (e.g., north of Japan and in Hudson Bay), the areas with the largest weekly SST variability are in (i) extratropical boundary and gyre-scale drift currents, such as the Gulf Stream and Kuroshio extensions; (ii) the Antarctic Circumpolar Current; and (iii) the central and eastern equatorial Pacific Ocean. For FIM-iHYCOM lead week 1 (Fig. 2b), the largest differences between simulated and observed SST variability are in the strong current regions just mentioned. The reduced SST variability in these regions is a consequence of iHYCOM's grid spacing of $\sim 60 \mathrm{~km}$, too coarse to adequately simulate eddying and meandering in extratropical current systems. (Even when observed 


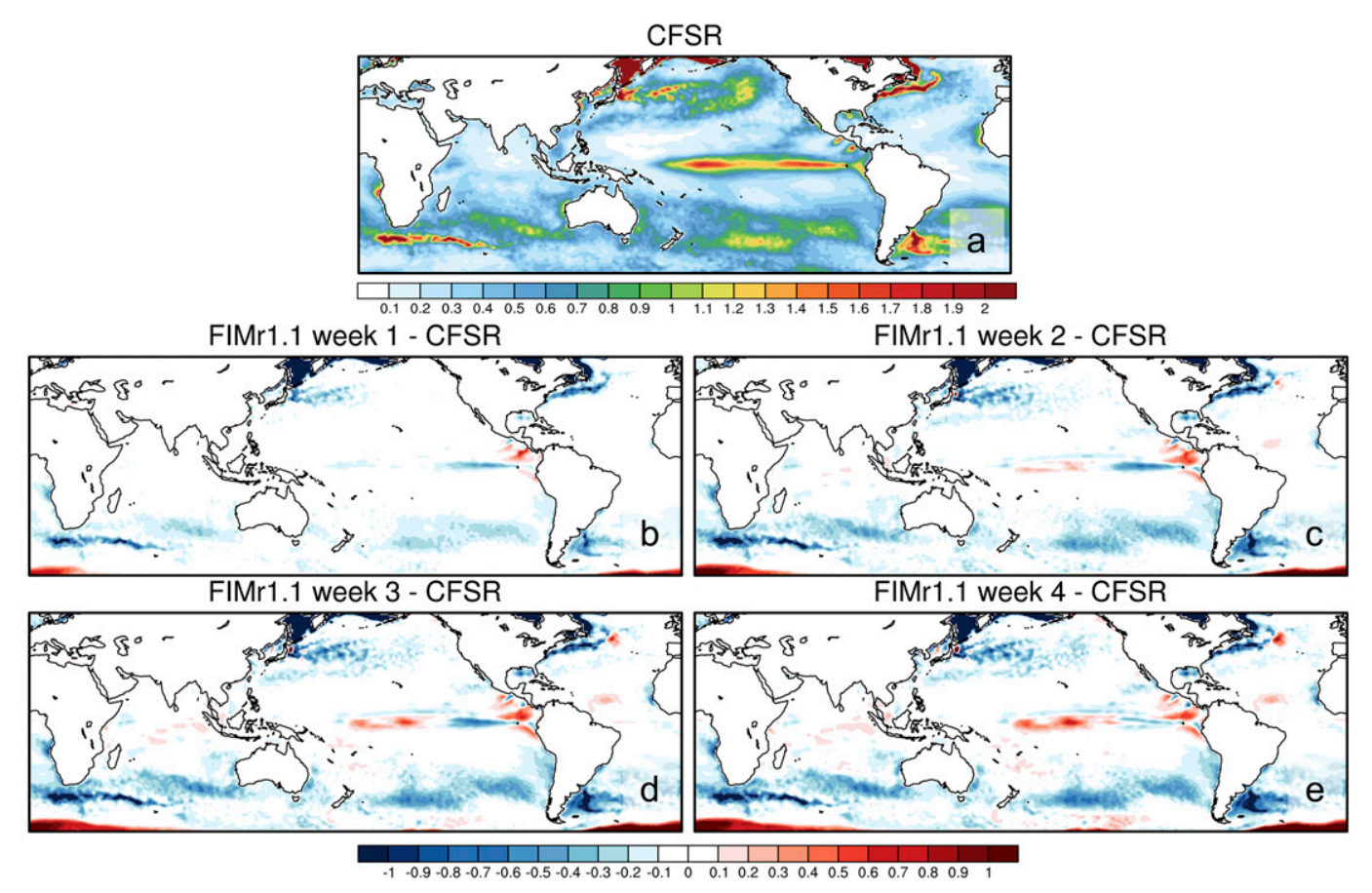

FIG. 2. (a) Variance of weekly averaged SST $\left(\mathrm{K}^{2}\right)$ for target season DJF from CFSR. (b)-(e) FIM-iHYCOM variance minus CFSR variance for lead weeks $1-4$, respectively.

SST is sampled at coarse resolution, as is done in CFSR, the effects of meandering and eddying on the largerscale ocean state are still captured to some extent.) The reduced SST variability in these regions (blue shading) appears to be nearly identical between weeks 3 and 4 (Figs. 2d,e). More interesting, though, is that by week 4, FIM-iHYCOM has higher SST variability than CFSR in the equatorial central Pacific, as well as in the equatorial Indian Ocean. An investigation of the potential impact of increased SST variability in FIM-iHYCOM (relative to CFSR, which may serve as a proxy for observed conditions) in the Indian Ocean on the MJO is beyond the scope of the present article. Overall, given that iHYCOM in its present configuration cannot resolve extratropical eddies, the coupled model appears to be effective in representing weekly SST variability.

\section{Skill of subseasonal hindcasts from FIM-iHYCOM and CFSv2}

Buizza and Leutbecher (2015) confirm the forecast skill of time-averaged fields of temperature, wind, and geopotential height to be significantly higher than that of time-averaged scores of instantaneous fields. (In their case, instantaneous fields had lower skill than 2-dayaveraged fields, which had lower skill than 8-day-averaged fields.) Zhu et al. (2014) evaluate model forecast skill by linking the averaging time window to the lead time as an approach to seamless verification across different time scales. In this section, we have opted to measure forecast skill based on weekly averages of model results (except in section 3c, in which daily data are used) on a $1^{\circ} \times 1^{\circ}$ horizontal grid. Recall from Part I that the native resolution of FIM-iHYCOM is $\sim 60 \mathrm{~km}$, while that of CFSv2 is $\sim 100 \mathrm{~km}$.

\section{a. Probabilistic skill of $T 2 m$ and precipitation}

In the NOAA-facilitated multimodel Subseasonal Experiment (SubX; NOAA 2017), each model was required to contribute at least four ensemble members. As stated earlier, FIM-iHYCOM uses four time-lagged members; CFSv2 currently has 16 members per day (as of 1 April 2011), but its hindcasts have only four members per day (cf. Part I).

With only four ensemble members, traditional "counting" methods to construct probabilistic forecasts (e.g., how many of the ensemble members exceed a certain threshold X) are of limited use. Fortunately, extended logistic regression [ELR; see Wilks (2009) for further details] can be used to construct a continuous range (bounded by $[0,1])$ of forecast probabilities. This technique was adopted by Vigaud et al. (2017) to use the ensemble mean forecast (and observed climatological terciles) as input into an ELR to create probabilistic forecasts of weekly precipitation on subseasonal time scales. Vigaud et al. (2017) used ELRbased probabilistic forecasts to look at both ranked 


\section{T2m RPSS, JFM}



T2m RPSS, JAS

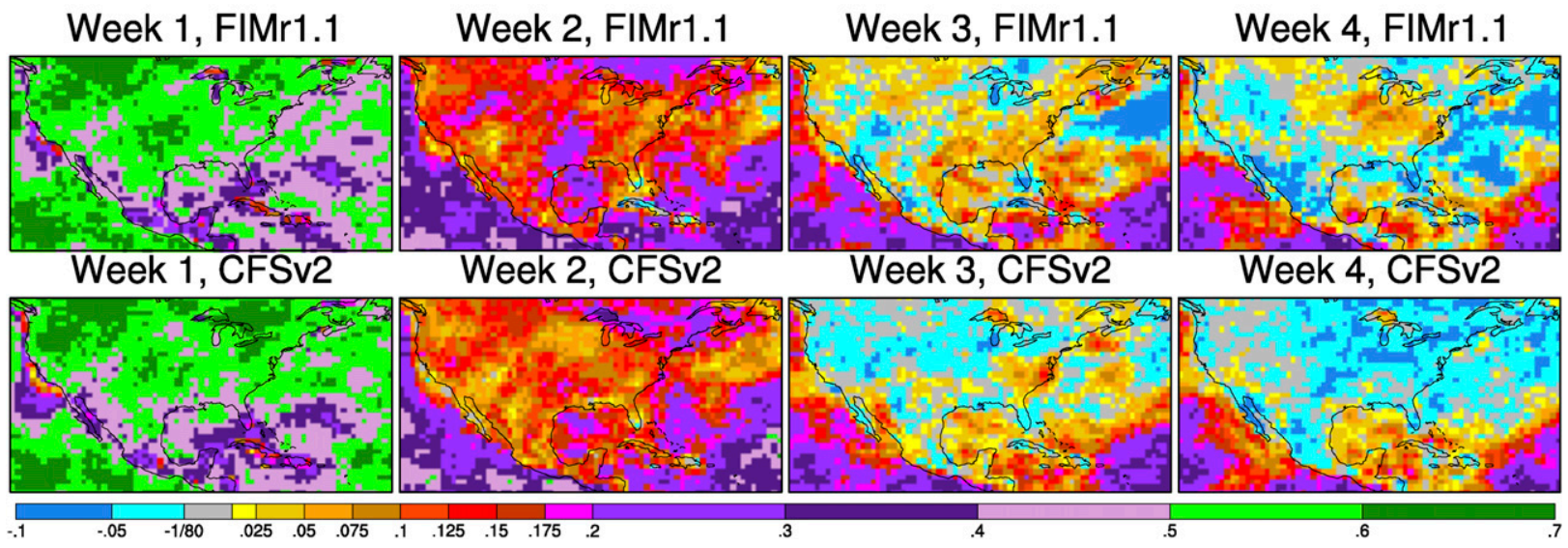

FIG. 3. RPSS for T2m forecasts, verified against CFSR, initialized in (top two rows) JFM and (bottom two rows) JAS for (rows 1 and 3 ) FIM-iHYCOM and (rows 2 and 4) CFSv2 over a region encompassing the conterminous United States. Lead weeks 1-4 are shown from left to right.

probability skill score (RPSS) and reliability diagrams for three S2S prediction systems, including the European Centre for Medium-Range Weather Forecasts (ECMWF) Ensemble Prediction System (EPS) and CFSv2. We evaluate FIM-iHYCOM's probabilistic skill for weekly averaged $\mathrm{T} 2 \mathrm{~m}$ and also for weekly accumulated precipitation. To do this, we follow a very similar methodology as that used by Vigaud et al. (2017). In short, this involves evaluating weekly forecasts initialized in either January-March (JFM) or July-September (JAS) over the period 19992010: this period was chosen in order to facilitate a direct comparison with Vigaud et al. (2017). FIM-iHYCOM results are compared with those from CFSv2 in Figs. 3-6. Moreover, the reanalyses used to build the ELR were CFSR for T2m and the Global Precipitation Climatology Project (GPCP; Huffman et al. 2001) for precipitation. We chose GPCP because (i) it incorporates both satellite measurements and ground observations and (ii) it was used by Vigaud et al. (2017) in their ELR.
It should be noted that bias correction in the manner used throughout much of this article was not employed for probabilistic forecasts; that is, the raw ensemble mean forecasts were used as input to the ELR. But by relating biased forecasts to reanalyses, the training of the regression model implicitly accounts for model bias. Given the fact that Vigaud et al. (2017) did not appear to apply bias correction a priori to the ensemble mean forecasts, we did not test the impact of a priori bias correction on the training of the ELR and the resultant ELR-computed forecast probabilities.

In this section, we compare the ability of FIM-iHYCOM and CFSv2 to predict below-normal, near-normal, and above-normal conditions for $\mathrm{T} 2 \mathrm{~m}$ and precipitation.

\section{1) RPSS}

The RPSS is one metric to assess probabilistic skill. As described by Wilks $(2006,299-302)$-note that "SS RPS " 


\section{Precip RPSS, JFM}

Week 1, FIMr1.1

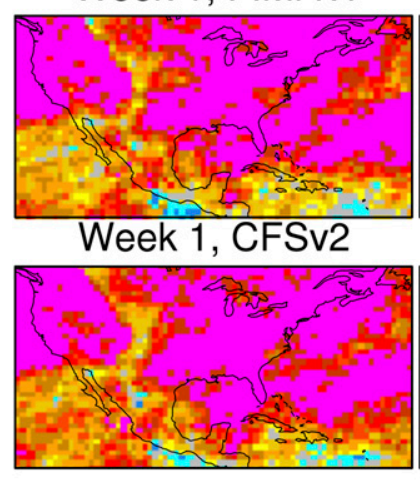

Week 2, FIMr1.1

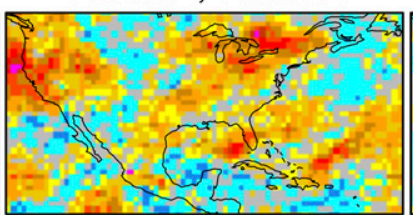

Week 2, CFSv2

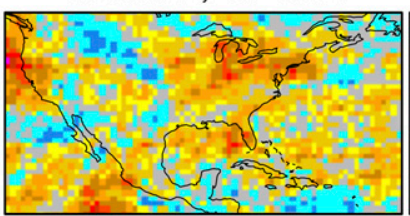

Week 3, FIMr1.1

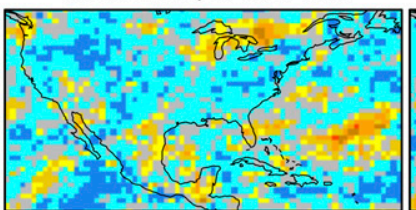

Week 3, CFSv2

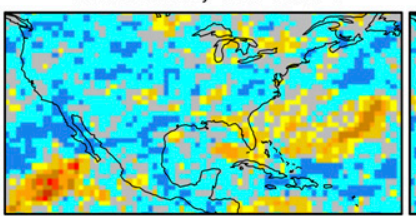

Week 4, FIMr1.1

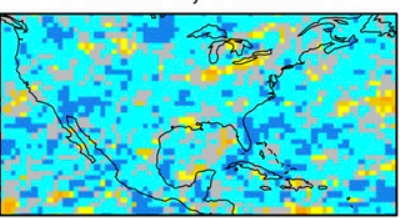

Week 4, CFSv2

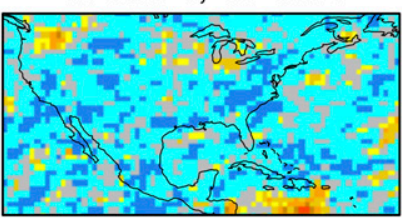

\section{Precip RPSS, JAS}



FIG. 4. As in Fig. 3, but for precipitation forecasts verified against GPCP. Note that the color bar matches that in Figs. 5 and 6 of Vigaud et al. (2017).

in his Eq. (7.49) is the same as RPSS-RPSS is useful for probabilistic forecasts of multicategory (three or more) events (e.g., below-, near-, or above-average temperature and precipitation). Positive values of RPSS indicate forecasts better than a climatological prediction (in this case, assigning a $1 / 3$ probability to each of the three categories). Figure 3 shows RPSS from FIM-iHYCOM and CFSv2 forecasts of T2m for JFM starts, as well as for JAS starts. Looking at JFM (top two rows of Fig. 3), both models have similar spatial distributions of RPSS for all four forecast lead weeks, but FIM-iHYCOM has more areas of nonnegative RPSS than CFSv2 for weeks 3 and 4. For JAS starts (bottom two rows of Fig. 3), again, FIM-iHYCOM has higher RPSS values than CFSv2 for weeks 3 and 4 . These results suggest that FIM-iHYCOM provides better probabilistic forecasts than CFSv2 of $\mathrm{T} 2 \mathrm{~m}$ at subseasonal time scales over the United States.

Figure 4 follows Fig. 3, respectively, but for forecasts of precipitation. RPSS for precipitation decreases much faster as a function of lead week than T2m, and the skill of FIM-iHYCOM is comparable to that of CFSv2. The much higher precipitation RPSS for CFSv2 week 1 in Fig. 4-compared with Figs. 5 and 6 of Vigaud et al. (2017) - is a consequence of the different days used to define week 1 [days 1-7 here; days 2-8 in Vigaud et al. (2017)]. By weeks 3 and 4, neither FIM-iHYCOM nor CFSv2 exhibits any cohesive areas of positive RPSS outside the tropics. Overall, the results are comparable to those shown in Figs. 5-6 of Vigaud et al. (2017) for the ECMWF EPS.

\section{2) RELiABILITY DiAgRAMS}

Reliability diagrams (e.g., Wilks 2006) provide a useful visualization of a model's probabilistic performance because they show the probability of observing an event (or of a variable exceeding a certain threshold), given a forecast probability of that same event (in our case, obtained from the ELR). On a reliability diagram, a perfect probabilistic forecasting system will have all points falling on the straight line $y=x$. 
FIMr1.1 JFM Below normal T2m

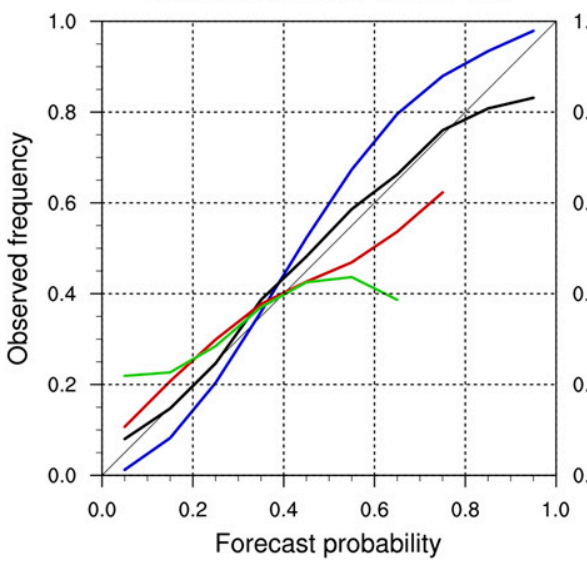

FIMr1.1 JFM Normal T2m

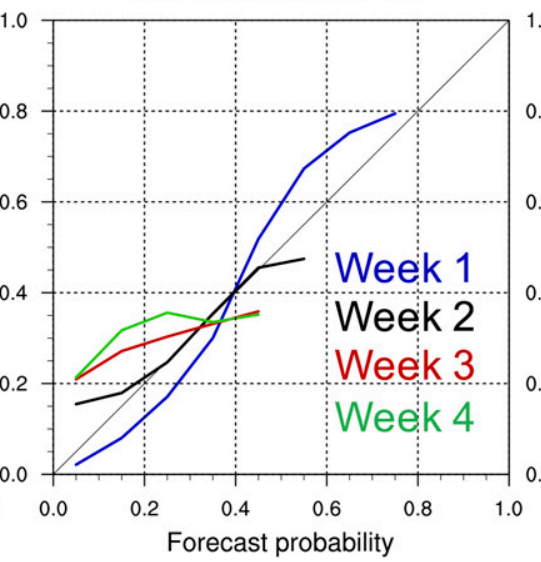

FIMr1.1 JFM Above normal T2m

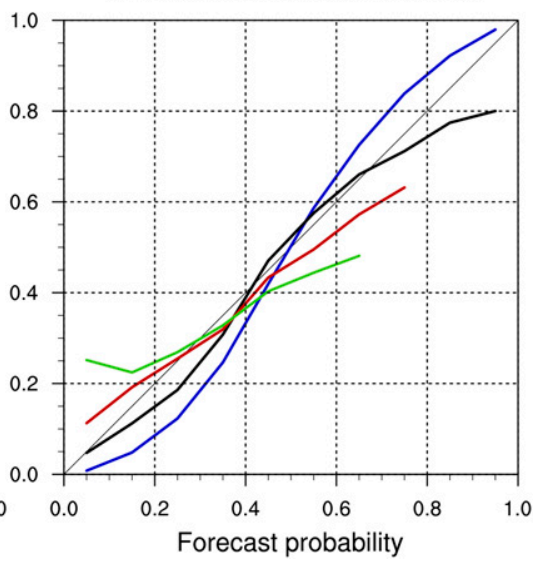

FIG. 5. Reliability diagrams for T2m forecasts (verified against CFSR) from FIM-iHYCOM, restricted to North American land points between $20^{\circ}$ and $50^{\circ} \mathrm{N}$ and initialized in JFM. Lead weeks $1-4$ are shown in different colors. Left to right: below-normal, near-normal, and above-normal categories.

Figure 5 shows reliability diagrams (but without the distribution of forecast probabilities) for below-, near-, and above-normal $\mathrm{T} 2 \mathrm{~m}$ for FIM-iHYCOM forecasts initialized in JFM, for all North American land points between $20^{\circ}$ and $50^{\circ} \mathrm{N}$ [following Figs. 3a-c of Vigaud et al. (2017)]. In week 1, T2m forecasts are all slightly underconfident (Wilks 2006, 288-289) but are overconfident by week 4 . Not surprisingly, the near-normal category is the hardest to predict (e.g., van den Dool and Toth 1991; Kharin and Zwiers 2003): after the first 2 weeks, there is no resolution-regardless of forecast probability, observed frequency is near $1 / 3$. For the below- and above-normal T2m categories, however, there is more reliability and resolution through week 3 . In week 4, the curves show losses in reliability and resolution, and the forecast probabilities (not shown) are concentrated on $1 / 3$. For all three categories, as lead time increases, the forecasts become less sharp (a smaller range of forecast probabilities is issued, and there is a tendency to forecast climatology). Overall, we find that FIM-iHYCOM can contribute to real-time prediction of $\mathrm{T} 2 \mathrm{~m}$ through at least 3 weeks of lead time.

Figure 6 is very similar to the top row of Fig. 3 in Vigaud et al. (2017). Here, reliability diagrams for precipitation based on FIM-iHYCOM forecasts initialized in JFM are shown aggregated over the same area as in Fig. 5. The slopes of the lines in these reliability diagrams all indicate an overconfident forecast by week 2 . Consistent with the RPSS results shown earlier, precipitation is more difficult to forecast than T2m. Again, the near-normal category is hardest to predict: after the first week, there is no resolution. For the below- and above-normal precipitation categories, however, there is some reliability and resolution through week 2 ; in weeks 3 and 4, there is no resolution, and the forecast probabilities (not shown) are concentrated on 1/3.

\section{b. Deterministic verification of selected fields}

\section{1) ANOMALy CORRELATION COEFFICIENTS}

Numerous variations on the theme of deterministic forecast skill assessment have appeared in the literature over the years. In the field of subseasonal prediction in particular, a "best" measure has yet to emerge. One commonly used skill metric for subseasonal verification so far (e.g., Saha et al. 2014; Zhu et al. 2014; Li and Robertson 2015; Lin et al. 2016) is the anomaly correlation coefficient (ACC), which we adopt here to quantify the skill of deterministic predictions.

We define weekly intervals the same way as in Part I (cf. Fig. 1 of that article), namely, days 1-7, 8-14, 15-21, and $22-28$ for weeks 1 to 4 , respectively. When we categorize target weeks by month, the day in the middle of the target week determines the target month (see section $2 b$ of Part I for a detailed description).

The ACC is calculated from

$$
\mathrm{ACC}=\frac{\sum_{k=1}^{K} \sum_{i=1}^{N}\left(f_{i, k}-F_{i}\right)\left(a_{i, k}-A_{i}\right)}{\sqrt{\sum_{k=1}^{K} \sum_{i=1}^{N}\left(f_{i, k}-F_{i}\right)^{2} \sum_{k=1}^{K} \sum_{i=1}^{N}\left(a_{i, k}-A_{i}\right)^{2}}} .
$$

Here, $N$ extends over all data points spanning the desired range of latitudes and longitudes; $K$ spans all hindcasts available. The $f_{i, k}$ are the ensembleaveraged model forecasts, and $a_{i, k}$ are the corresponding (re)analysis values, both weighted by the cosine of latitude to account for meridian convergence in the 
FIMr1.1 JFM Below normal Precip

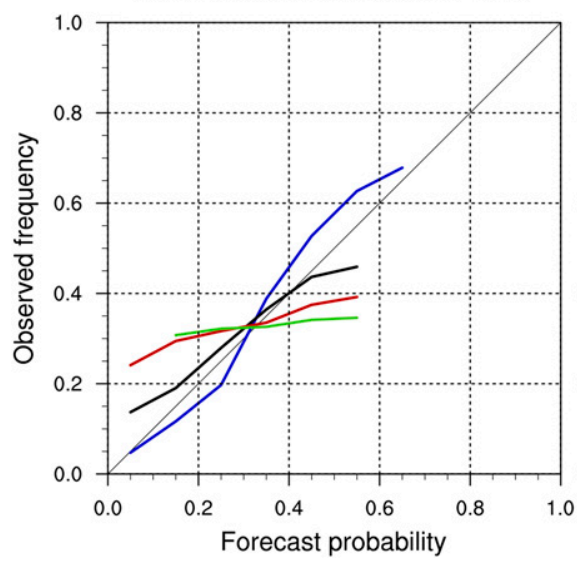

FIMr1.1 JFM Normal Precip

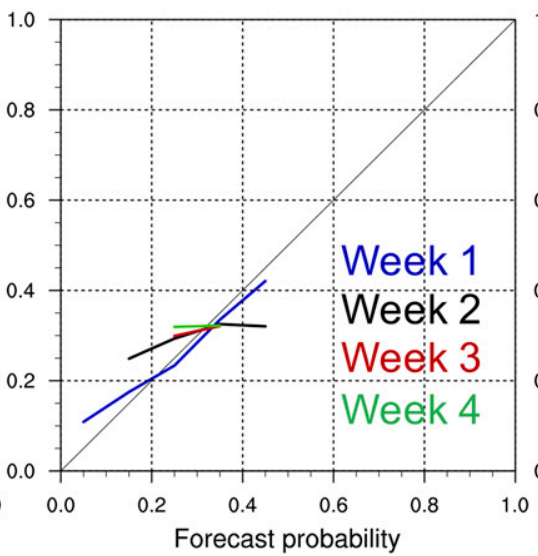

FIMr1.1 JFM Above normal Precip

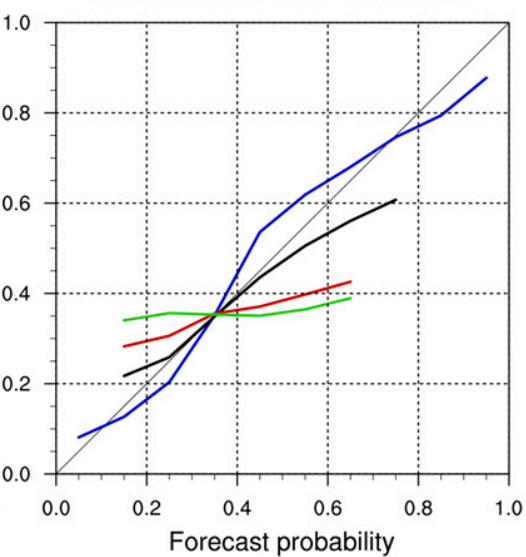

FIG. 6. As in Fig. 5, but for precipitation forecasts verified against GPCP.

latitude-longitude grid; $F_{i}, A_{i}$ are the forecast and (re) analysis climatologies at each latitude-longitude grid point $i$.

We verify ensemble mean forecasts of $\mathrm{T} 2 \mathrm{~m}$ and 500-hPa geopotential height (H500) against CFSR. Precipitation is verified against GPCP during the period of 1999 to 2014.

Figure 7 shows the geographic distributions of the ACC over North America for forecasts of T2m from both FIM-iHYCOM and CFSv2. As in Part I, and in section $2 \mathrm{~b}$ here, the results are composited based on target season: 14 for DJF and 16 for JJA. There are 196 cases in DJF and 224 cases in JJA, which implies that an ACC value of $\sim 0.1$ is statistically significantly greater than zero (at the $95 \%$ confidence level) based on a Student's $t$ test. There is clearly a substantial contrast in $\mathrm{T} 2 \mathrm{~m}$ skill between ocean and land (T2m over the ocean is strongly influenced by slowly evolving sea surface temperatures), which is why Figs. 9 and 11 (see below) only consider land points for T2m. Despite an overall rapid decrease in T2m ACC over land after week 2, there is some statistically significant skill in the southeastern United States beyond week 2. For a given target season (DJF or JJA), FIM-iHYCOM has comparable ACCs with CFSv2. Over land, DJF generally has higher ACCs than JJA for a given lead week; the opposite is the case for points over water. The last row of Fig. 7 shows the ACCs of 2-week (14 day) forecasts for weeks 3 and 4 combined. This is along the line of seamless verification in which the temporal averaging window increases as lead time increases (e.g., Zhu et al. 2014). There are regions in which the ACCs of the combined weeks 3-4 forecasts of $\mathrm{T} 2 \mathrm{~m}$ are higher (although not necessarily statistically significantly higher) than the ACCs of the week 3 forecast. This lends further support to the notion that for subseasonal prediction, useful information could be extracted from a combined weeks 3-4 forecast that might not be evident when considering weeks 3 and 4 separately.

The skill of precipitation is generally quite low beyond week 1 (e.g., Zhu et al. 2014; Li and Robertson 2015). Recent studies have shown that forecast skill at weeks 3 and 4 may be higher than previously thought, via use of more sophisticated data analysis techniques (DelSole et al. 2017) and/or by targeting periods with known sources of predictability (Vigaud et al. 2017). Figure 8 follows Fig. 7, but for precipitation. Although ACCs drop rapidly after week 1 , there is some skill along the West Coast of the United States at weeks 2 and 3, especially in DJF. As with $\mathrm{T} 2 \mathrm{~m}$, for precipitation there are some areas (mainly in the subtropics) in which the combined weeks 3-4 ACCs (bottom row of Fig. 8) are higher than the week 3 ACCs. Overall, FIM-iHYCOM and CFSv2 have similar precipitation ACCs, despite the fact that they employ very different convective parameterizations [modified Grell and Freitas (2014) for FIM-iHYCOM; Simplified Arakawa-Schubert (e.g., Han and Pan 2011) for CFSv2]. In general, the ACCs from both FIM-iHYCOM and CFSv2 are comparable to the Predictive OceanAtmosphere Model for Australia (POAMA; cf. Zhu et al. 2014; Wheeler et al. 2017) and CFSv2 and EPS in $\mathrm{Li}$ and Robertson (2015).

Figure 9 compares the ACCs at different lead times of weekly averages in DJF and JJA for T2m (aggregating all land points in the Northern Hemisphere), as well as for precipitation and $\mathrm{H} 500$ (both aggregated over all points from $20^{\circ}$ to $80^{\circ} \mathrm{N}$ ), from both FIM-iHYCOM and CFSv2. In addition to weekly averages, the 2-week average of weeks 3 and 4 is shown. The ACCs from both models are very similar and, not surprisingly, decrease with increasing lead time. Aggregated ACCs remain above zero through 4 weeks and are mostly higher in 
T2m ACC, DJF
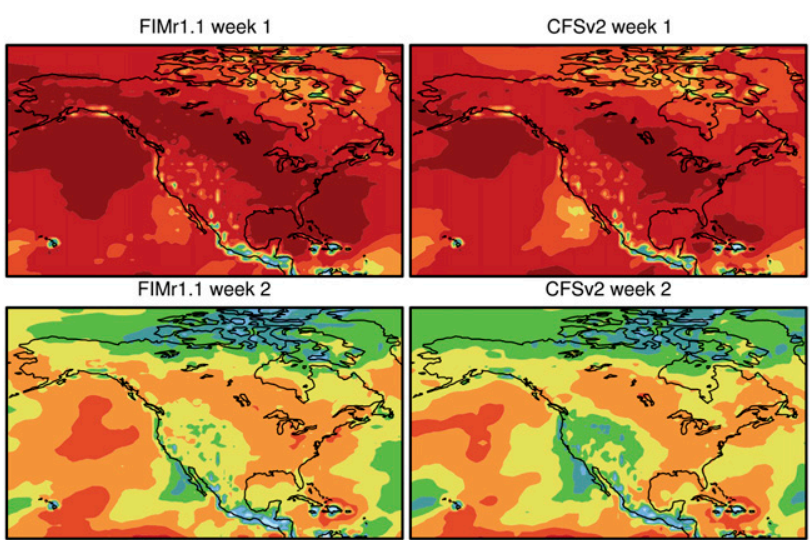

FIMr1.1 week 3

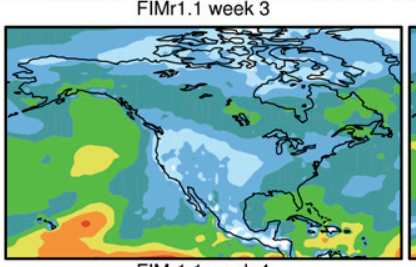

FIMr1.1 week 4

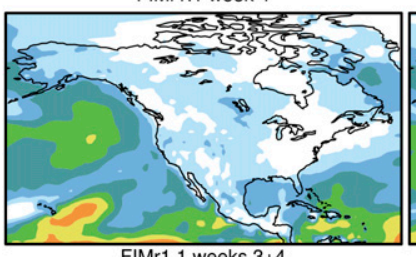

FIMr1.1 weeks $3+4$

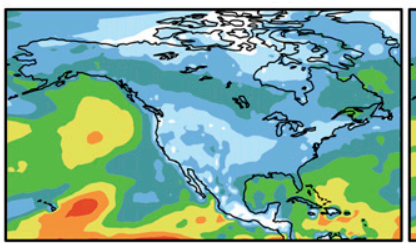

0.1
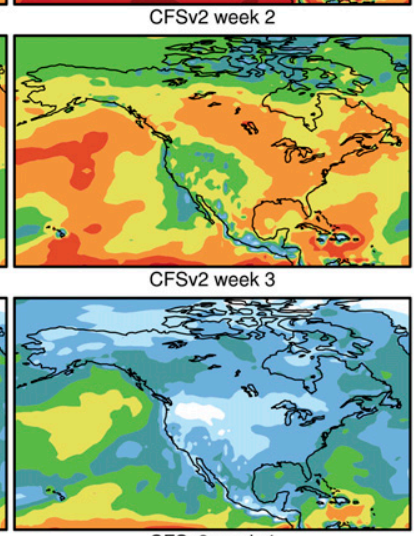

FSv2 week 4

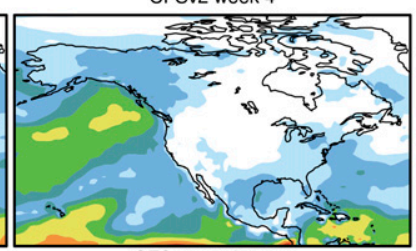

CFSv2 weeks $3+4$

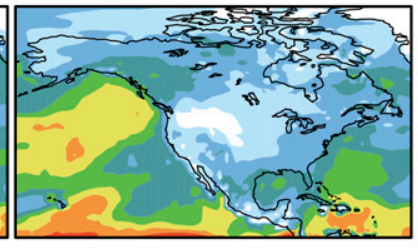

0.3
CFSv2 week 3

T2m ACC, JJA
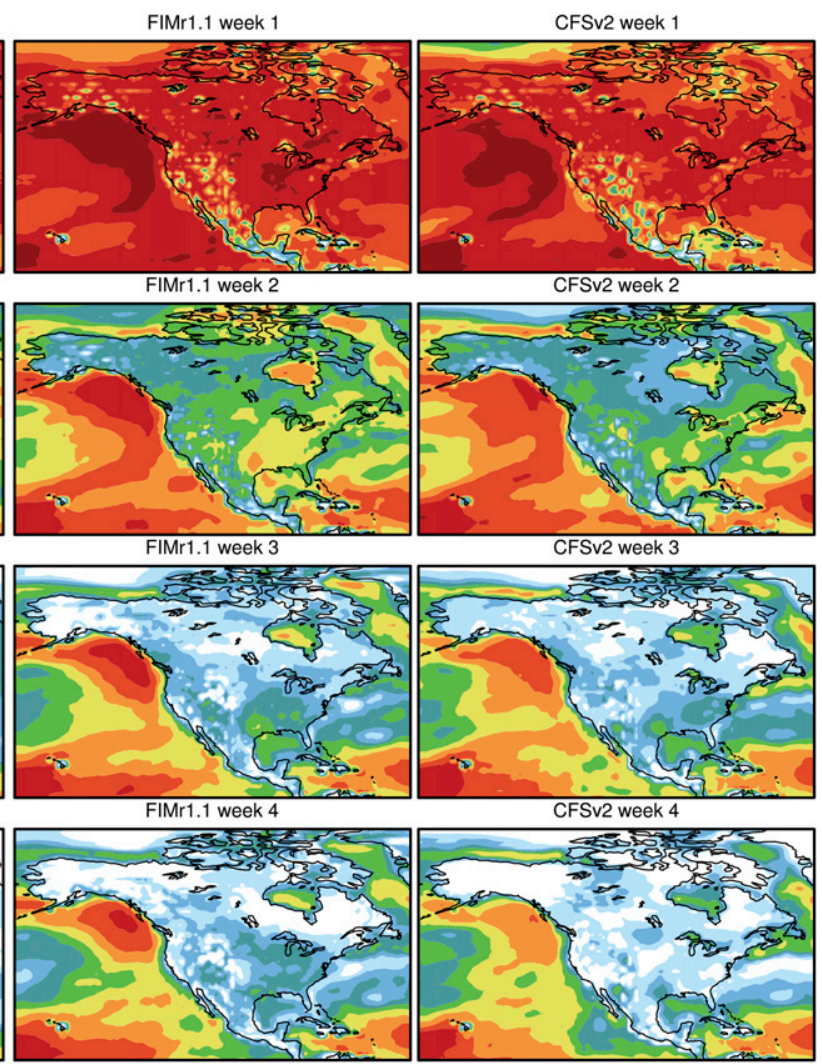

FIMr1.1 weeks $3+4$
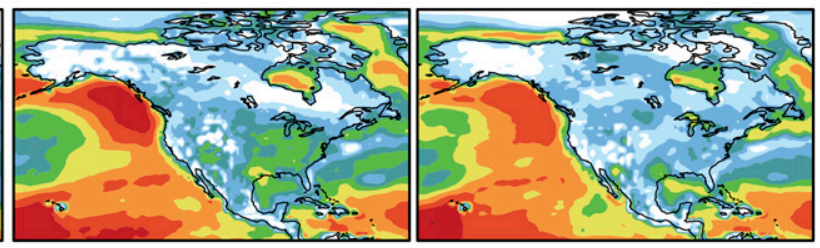

FIG. 7. Maps of T2m ACCs for (left two columns) DJF and (right two columns) JJA from (columns 1 and 3) FIM-iHYCOM and (columns 2 and 4) CFSv2 at lead times of (top four rows) 1-4 weeks. (bottom) ACCs as computed from the average of weeks 3 and 4. Values of ACC $\geq \sim 0.1$ are significantly different from zero (at $95 \%$ confidence).

DJF than in JJA. Consistent with Figs. 7 and 8, the ACCs of the combined weeks $3-4$ average forecast is close to that of the week 3 ACCs and higher than the week 4 ACCs.

Figure 10 shows the geographic distributions of H500 ACCs for both FIM-iHYCOM and CFSv2, similar to Figs. 7 and 8. Consistent with Fig. 9, H500 ACCs through week 3 are higher in DJF than in JJA. Also consistent with Fig. 9 is the fact that FIM-iHYCOM and CFSv2 have very similar Northern Hemisphere ACC magnitudes. A higher level of skill is seen in the North Pacific for all lead weeks in both models, especially in DJF.

In summary, the ACCs of $\mathrm{T} 2 \mathrm{~m}$, precipitation, and H500 in FIM-iHYCOM are comparable to those from
CFSv2. They are also comparable to those found in other subseasonal prediction systems, including the Canadian Global Ensemble Prediction System (GEPS) shown by Lin et al. (2016) when evaluated using the definitions of weekly averages and target months in their study (not shown), although the spatial patterns differ. These skills are, in general, higher in the winter season than in summer, as found in other studies (e.g., Kirtman et al. 2014; Zhu et al. 2014; Lin et al. 2016; DelSole et al. 2017), possibly due to the relative dominance in winter of wellresolved synoptic-scale processes such as baroclinic instability, as opposed to mesoscale and convection-scale processes that are poorly resolved and represented. 




FIG. 8. As in Fig. 7, but for precipitation.

\section{2) SPREAD-ERROR RELATIONSHIP}

Two other metrics commonly used to assess model skill are root-mean-square error (RMSE) and ensemble spread. In ensemble prediction, it is important that the RMSE of the ensemble mean is of comparable magnitude to the ensemble spread of the field in question, as they are, for example, in Fig. 1 of Fortin et al. (2014). In general, an ensemble spread that is substantially smaller than (greater than) the RMSE of the ensemble mean indicates an ensemble that is underdispersive (overdispersive). In either case, the ensemble probability distribution poorly represents the true probability distribution; the interested reader is referred to the statistically based discussion of Fortin et al. (2014). We calculated the spread using the right-hand side of Eq. (15) of Fortin et al. (2014), reproduced here for convenience:

$\mathrm{RMSE} \approx \sqrt{\left(\frac{R+1}{R}\right) \frac{1}{T} \sum_{t=1}^{T} s_{t}^{2}}=\sqrt{\left(\frac{R+1}{R}\right)}\left(\overline{s_{t}^{2}}\right)^{1 / 2}$

Here, $R$ is the ensemble size ( 4 for the case of FIM-iHYCOM), $T$ is the number of cases (hindcast weeks for FIM-iHYCOM), and $s_{t}^{2}$ is the ensemble variance for case (week) $t$. The term under the radical symbol on the far right-hand side of (2) accounts for ensemble size (without this, spread would be less than error simply due to the small number of ensemble members). The results are shown in Fig. 11 for T2m, precipitation, and H500 (all three 
T2m NH LAND DJF
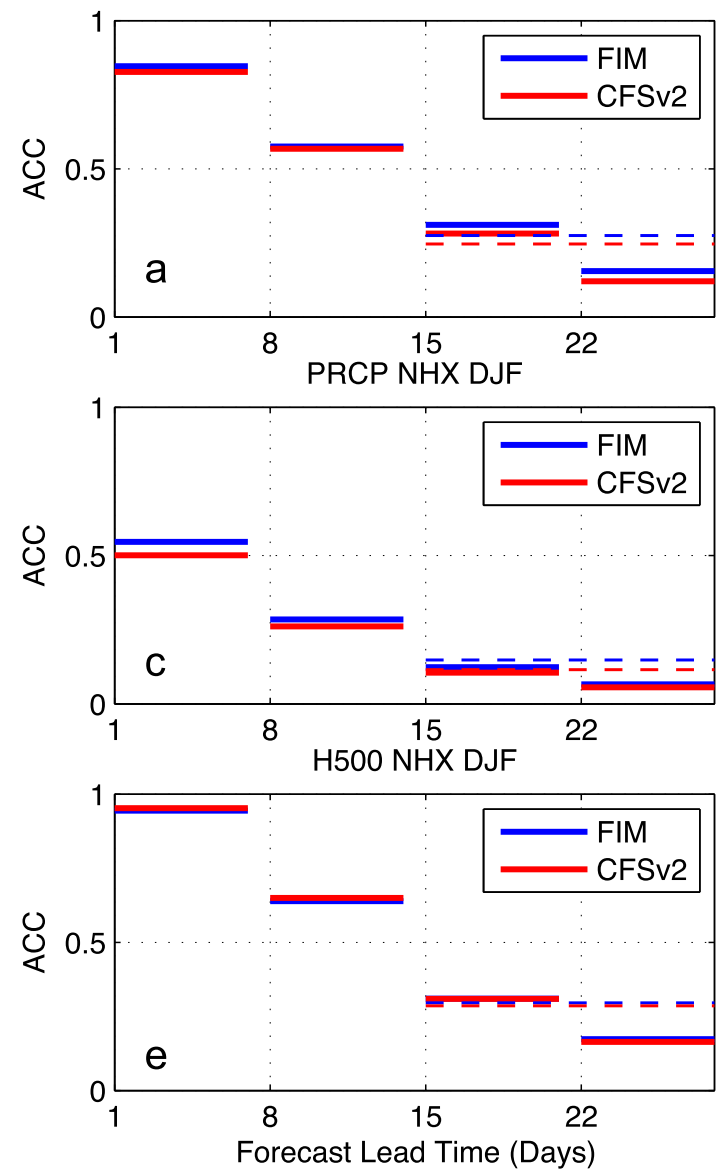

T2m NH LAND JJA
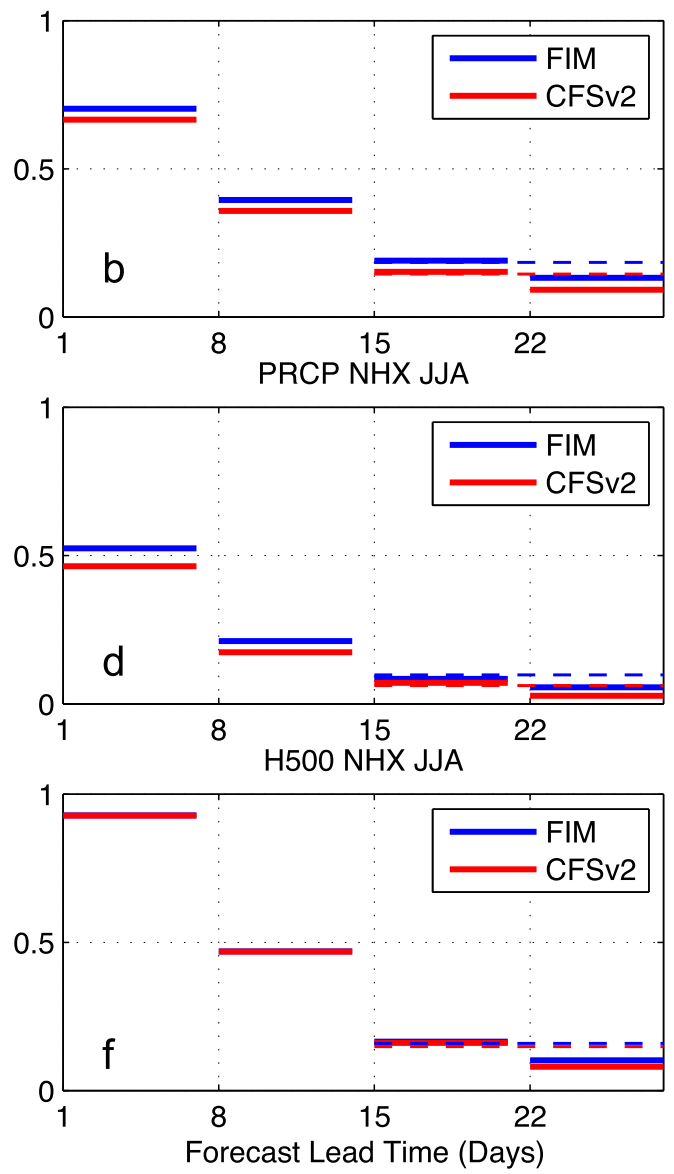

FIG. 9. ACCs for FIM-iHYCOM (blue) and CFSv2 (red) forecasts as a function of forecast lead week (1-4) for target seasons (left) DJF and (right) JJA. (a),(b) T2m over land points in the Northern Hemisphere. (c),(d) Precipitation between $20^{\circ}$ and $80^{\circ} \mathrm{N}$. (e),(f) H500 between $20^{\circ}$ and $80^{\circ} \mathrm{N}$. Dashed lines show the ACCs computed from the average of weeks 3 and 4 .

fields composited over the same regions used for Fig. 9) as a function of lead time for both FIM-iHYCOM and CFSv2. Overall, the two models are comparable in terms of their RMSE and spread. For T2m and H500, the models are underdispersive (spread $<$ RMSE) even after accounting for the small ensemble size; however, for precipitation, CFSv2 (and, to a lesser extent, FIM-iHYCOM) have some instances in which spread exceeds error, likely owing to the highly non-Gaussian nature of precipitation. The underdispersive (overconfident) nature of the $T 2 \mathrm{~m}$ results in Fig. 11a is consistent with the shape of the reliability diagrams (Fig. 5) for weeks 3 and 4.

\section{c. Prediction of various subseasonally relevant phenomena}

\section{1) BLOCKING FREQUENCY}

Many extreme weather events, such as heat waves and flooding, are found to be associated with episodes during which the normal midlatitude zonal flow is temporarily blocked by a meridionally aligned cyclone-anticyclone couplet often referred to as a modon (Flierl et al. 1980). Early studies (e.g., Miyakoda et al. 1983) have suggested that there is some predictability for blocking at lead times up to 1 month; more recent work (e.g., Matsueda 2011) has shown examples of blocking impacting weather on multiweek time scales. Thus, it is important to examine a model's ability to simulate blocking at subseasonal time scales. Furthermore, reproducing realistic blocking frequency is considered to be necessary, though not sufficient, for skillful forecasts of blocking. In light of the many shapes and forms of midlatitude blocks, which a single blocking index may not be able to account for satisfactorily, we document their frequency and geographic distribution by relying on two different blocking indices.

The first index is the widely used Tibaldi and Molteni (1990) blocking frequency index (TM index hereafter), 


\section{H500 ACC, DJF}

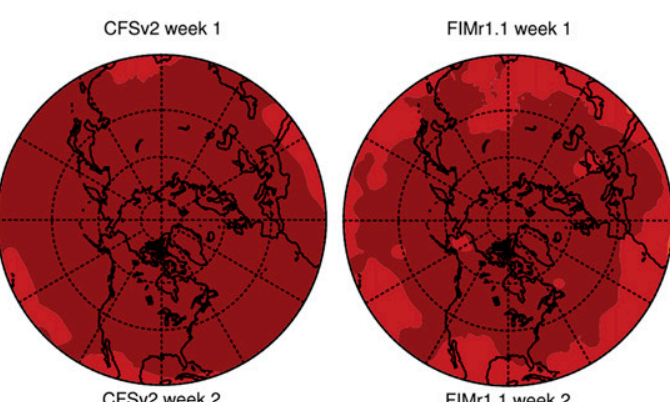

H500 ACC, JJA
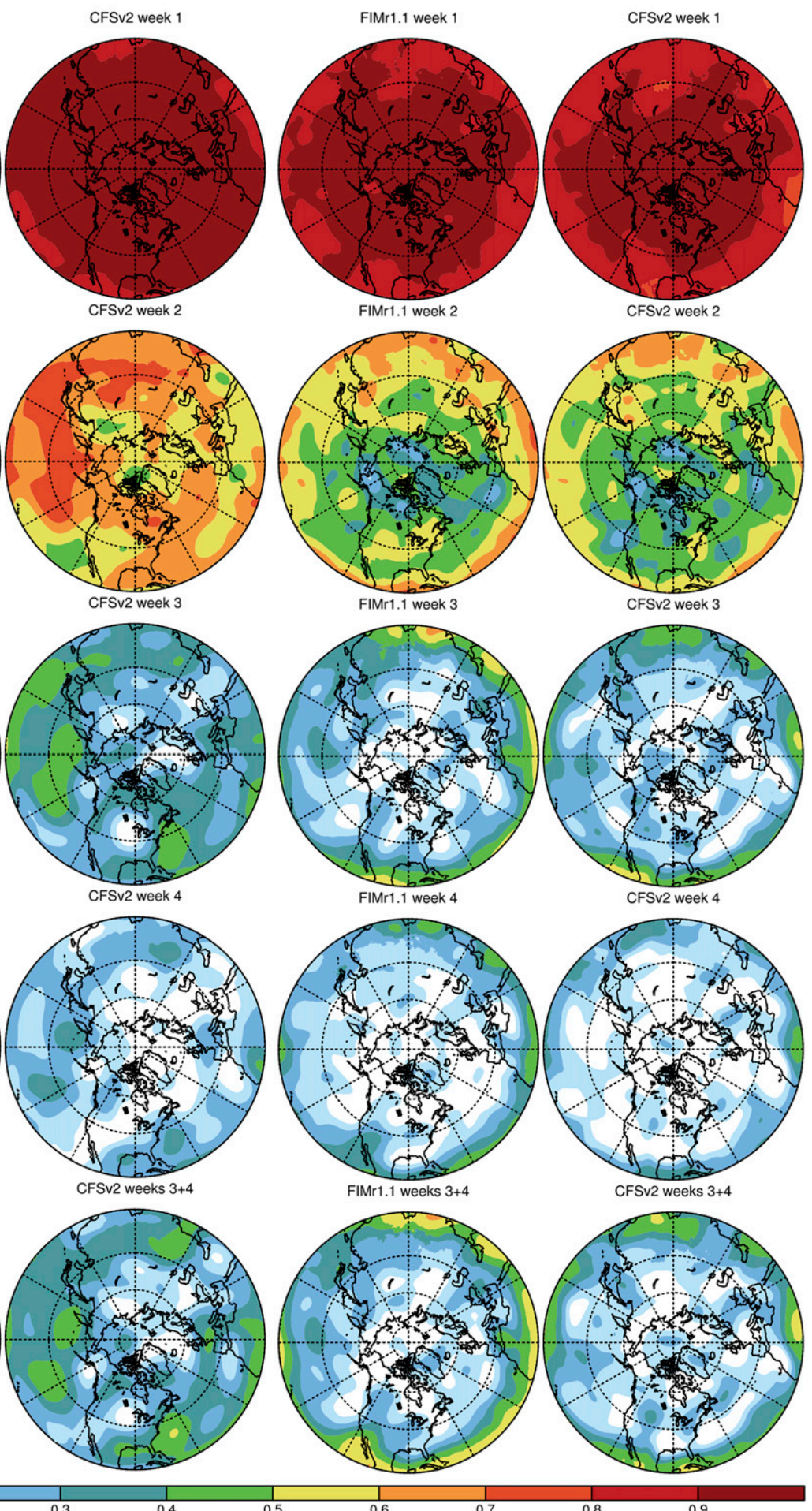

FIG. 10. As in Figs. 7 and 8, but for H500. 
RMSE (solid) and Spread (dashed)
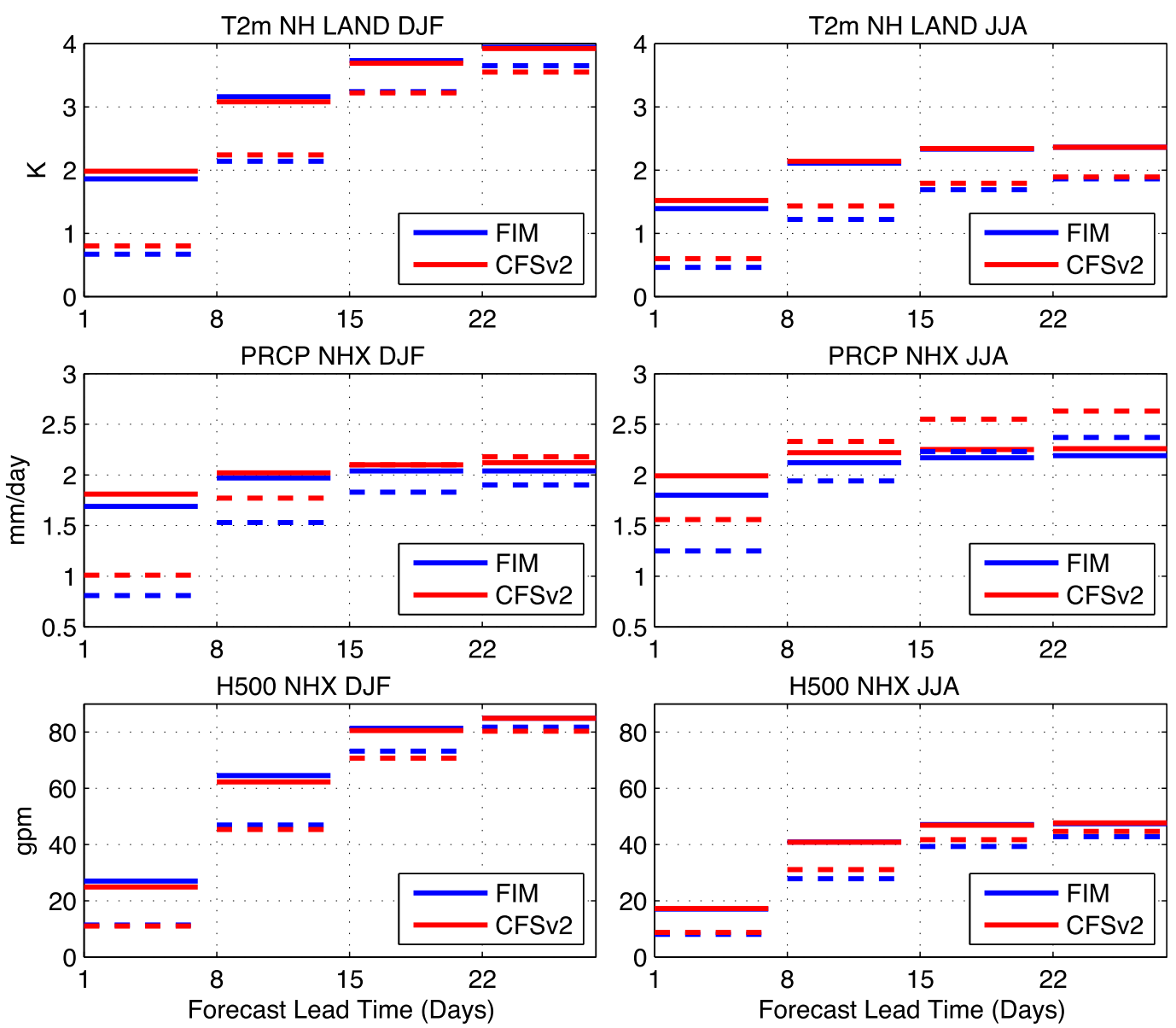

FIG. 11. As in Fig. 9, but for RMSE (solid) and spread (dashed). Units of RMSE and spread for T2m, precipitation, and $\mathrm{H} 500$ are $\mathrm{K}, \mathrm{mm} \mathrm{day}^{-1}$, and gpm, respectively. The geographic areas over which RMSE and spread are computed match those of Fig. 9.

which is essentially based on the reversal of the meridional gradient of $\mathrm{H} 500$ at midlatitudes. In addition to identifying so-called "instantaneous" blocks (which, in this case, are blocks identified by the TM index for a single day of the daily averaged H500 field), the original TM index definition also has an option to add a longevity threshold to blocking identification. Including a temporal threshold (for this article, a minimum of 4 days) means only persistent blocks are identified. The challenge to the forecast model is not merely to predict blocking events per se, but to predict the long-lived ones correctly, as the latter often lead to extreme weather.

The second blocking index, developed by Pelly and Hoskins (2003; PH index hereafter), is arguably a more physical alternative to the TM index. It is based on a reversal of the meridional potential temperature gradient on a tropopause-level potential vorticity $(\mathrm{PV})$ isosurface within a latitude range centered on the longitude-dependent mean storm track. The latter refinement gives the $\mathrm{PH}$ index some advantage over the TM index, whose meridional search interval is independent of longitude. The PH index emphasizes temperature gradient reversals near the tropopause-that is, at the edge of the stratospheric surf zone (McIntyre and Palmer 1984) - compared to those evident in the midtroposphere detected by the TM Index.

Figure 12 shows the blocking frequency from FIM-iHYCOM and CFSv2 at selected forecast lead times from days 7 to 28 . It is based on the full $16-\mathrm{yr}$ forecast period (no seasonal restriction) of the weekly initialized four-member ensembles, where each member is treated as an independent forecast-no ensemble means are considered. The solid curves in all panels are based on the TM index. No temporal threshold is used in Figs. 12a and 12b, whereas a 4-day temporal threshold to capture blocking "episodes" is used in Figs. 12c and 12d. 
FIM-iHYCOM
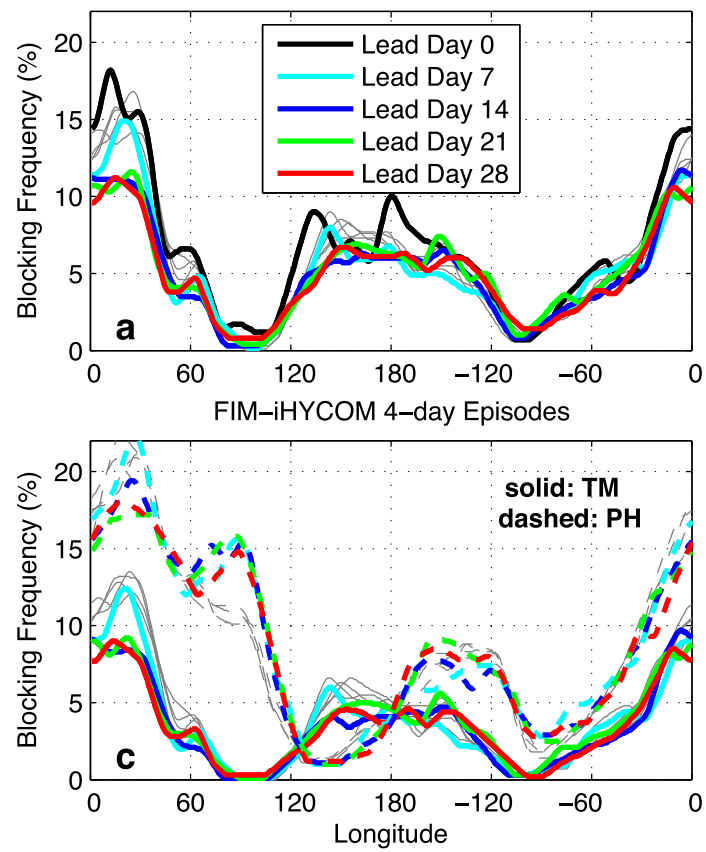

CFSv2


FIG. 12. Northern Hemisphere blocking frequency as a function of longitude from 16 years (1999-2014) of ensemble forecasts (each member treated as an independent sample) for lead times of 7, 14, 21, and 28 days. (a) Solid lines: TM index extracted from weekly sampled four-member FIM-iHYCOM hindcasts with no temporal threshold. Gray lines: TM index based on bias-corrected H500; colored lines: TM index based on H500 without bias correction. (b) As in (a), but for CFSv2. (c),(d) As in (a),(b), but with a temporal threshold of 4 days. PH index (dashed lines) added in (c). "Lead Day 0" (initial conditions) added in (a),(b) as proxy for reanalysis.

Because of the noisy nature of the derived blocking frequency, which is unavoidable given the limited sample size, all curves are longitudinally smoothed using 15 passes of the nine-point low-pass filter described in the appendix. (This number of passes was found to remove wave components of roughly $20^{\circ}$ of longitude and shorter.) As a proxy for observed conditions, the blocking frequencies from each model's initial conditions (day 0) are also shown in the top panel. ${ }^{2}$

From the perspective of the TM index, FIM-iHYCOM and CFSv2 show similar blocking frequency at all lead weeks-specifically, a frequent Euro-Atlantic block and a weaker Pacific block. The slight decline in blocking frequency with lead time seen in the FIM-iHYCOM results appears to be related to excessive deepening of troughs over the high-latitude ocean basins (not shown), which has the effect of lowering the probability of H500 gradient reversals. This declining trend is largely removed

\footnotetext{
${ }^{2}$ Recall from Part I that the initial conditions for both FIM-iHYCOM and CFSv2 come from CFSR; thus, the small differences in the black curves in Fig. 12 (between the two models) are a consequence of interpolating to the FIM-iHYCOM native icosahedral grid before all data are interpolated to $1^{\circ} \times 1^{\circ}$.
}

by the bias correction, as shown in the gray curves. Given the fact that different time periods are used here, it is not surprising that the blocking frequency shown in Figs. 12a and 12b differs from Jung et al. (2012) for the ECMWF model and Hamill and Kiladis (2014) for the NOAA GEFS model, both also being based on the TM index. Applying the 4-day duration filter lowers the TM blocking frequency by about $30 \%$, as shown in Figs. 12c and $12 \mathrm{~d}$.

The dashed lines in Fig. 12c show the frequency of 4-day blocking episodes in FIM-iHYCOM as measured by the PH index. As discussed by Pelly and Hoskins (2003), the southward displacement of the storm tracks over the western and central Pacific limits the ability of many blocks identified by the TM index to actually interfere with the westerly flow in that region. The $\mathrm{PH}$ index corrects for that and, in the process, shifts the Pacific blocking maximum eastward relative to the one generated by the TM index. This shift, a definite improvement from the synoptic meteorology perspective, is quite noticeable in Fig. 12c. Our results confirm the finding of Pelly and Hoskins (2003) that their tropopause-based index captures more blocking events than does the TM index, especially over Europe. 

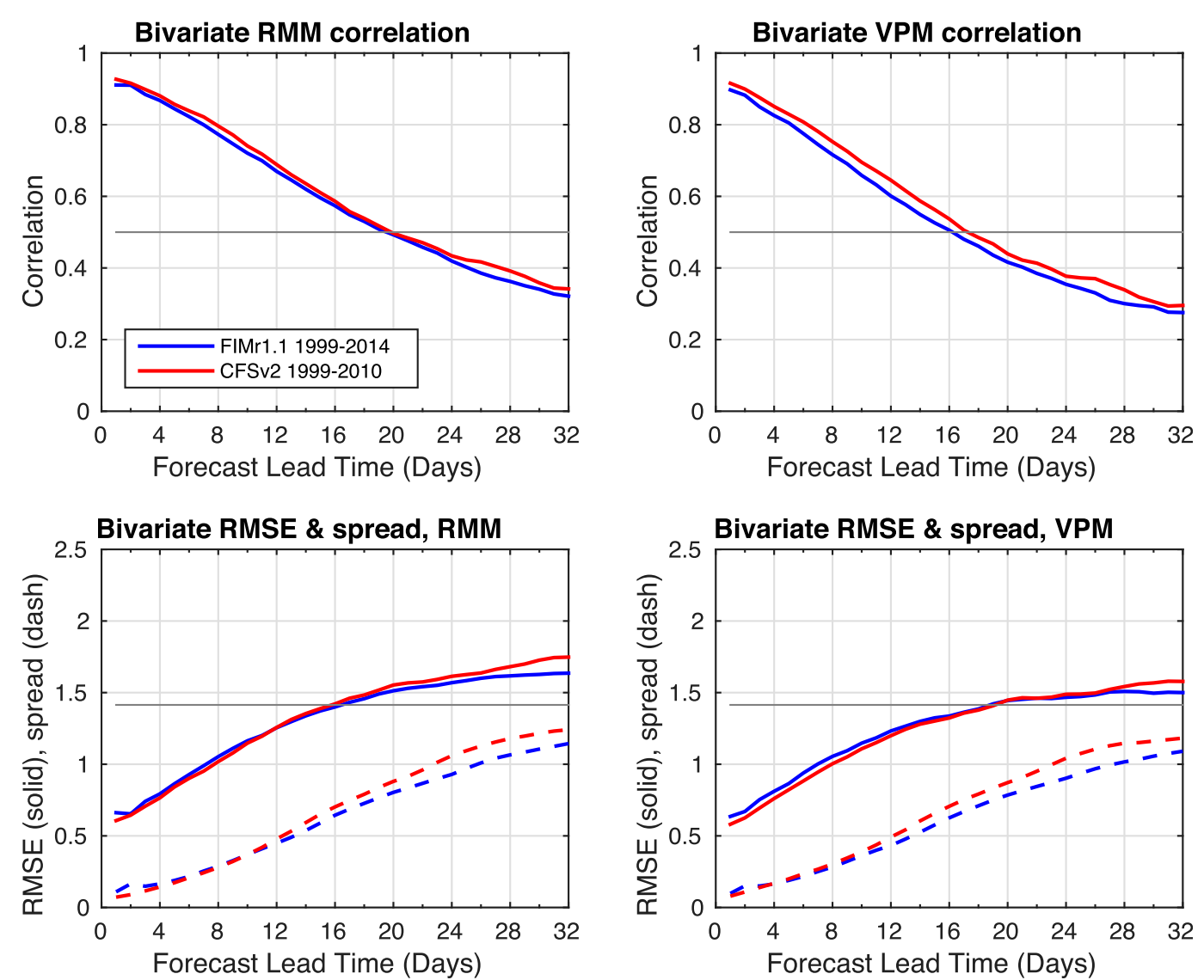

FIG. 13. Model performance as a function of lead time for FIM-iHYCOM (blue) and CFSv2 (red) ensemble mean forecasts of the (left) RMM index and (right) VPM index [as in Green et al. (2017)]. (top) Bivariate correlation (gray line $=0.5$ ). (bottom) Bivariate RMSE (solid; gray line $=\sqrt{2}$ ) and four-member ensemble spread (dashed).

Because of the use of an isentropic vertical coordinate (including a prognostic equation for layer thickness, the denominator in the PV expression) the PV field generated by FIM contains details not resolved in models employing a conventional fixed vertical grid. For this reason, we refrain from comparing $\mathrm{PH}$-index-based blocking statistics between FIM-iHYCOM and CFSv2, focusing instead on a comparison of the two blocking indices in FIM-iHYCOM forecasts.

\section{2) MADDEN-JULian OSCILlation}

As discussed in Part I, the Madden-Julian oscillation is seen as important for subseasonal time scales because it is responsible for most of the 30-90-day tropical variability (Zhang 2005) and impacts the entire Earth system (Zhang 2013); therefore, a good representation of the MJO in FIM-iHYCOM is necessary, but not sufficient, to provide reasonably skillful subseasonal forecasts. Green et al. (2017) provide a detailed analysis of the overall ability of an earlier version of FIM-iHYCOM to simulate two different $\mathrm{MJO}$ indices (and the corresponding input fields). The key differences between the hindcasts in Green et al. (2017) and those shown here are detailed in section $2 \mathrm{a}$ of Part I.

Figure 13 compares the CFSv2 results [over the period 1999-2010, as in Green et al. (2017)] with the full 16-yr FIM-iHYCOM hindcast period ${ }^{3}$ in terms of ability to predict a variant of the Real-time Multivariate MJO (RMM) index (cf. Wheeler and Hendon 2004; Green et al. 2017) and a similar variant of the Velocity Potential MJO (VPM) index (cf. Ventrice et al. 2013; Green et al. 2017). Both indices require daily (i.e., not weekly) data. Figure 13 follows the methodology of Green et al. (2017), with one major exception: in Green et al. (2017), reanalysis climatology was used, whereas here, model climatologies (for both FIM-iHYCOM and CFSv2) were used (i.e., bias correction described in section $2 \mathrm{a}$ above was applied). It should be noted here that the verifications for RMM and VPM shown in Fig. 13 are

\footnotetext{
${ }^{3}$ The impact of including FIM-iHYCOM hindcasts from 2011 to 2014 is deemed negligible (not shown).
} 
based on the NCEP-NCAR reanalysis (Kalnay et al. 1996) rather than CFSR. The present hindcast configuration of FIM-iHYCOM exhibits RMM skill [often defined as exceeding a threshold of 0.5 for the bivariate correlation; e.g., Rashid et al. (2011)] out to $\sim 19$ days, essentially the same as that of the CFSv2 hindcast (Fig. 13); VPM skill is $\sim 16$ days for FIM-iHYCOM and $\sim 18$ days for CFSv2. The RMM skill of CFSv2 is consistent with what is shown in Wang et al. (2014). Overall, the performance of the present hindcast in terms of RMM and VPM is comparable to the results shown in Green et al. (2017) for their earlier version of FIM-iHYCOM, not just for bivariate correlation, but also for RMSE (both models are comparable; note also that RMSE $<\sqrt{2}$ represents errors less than those of a climatological forecast) and spread (both models are underdispersive). One notable exception is that the current FIM-iHYCOM hindcast for RMM performs better (but not necessarily statistically significantly so) than that used by Green et al. (2017) in terms of both higher correlations and lower RMSEs during the first $\sim 8$ days; interestingly, this cannot be explained by the inclusion of bias correction in the present hindcast (not shown).

\section{3) SUDDEN STRATOSPHERIC WARMING}

Upward propagation of zonal wavenumber-1 or -2 planetary waves into the upper polar stratosphere-which typically occurs during periods of weak high-latitude stratospheric westerlies (Charney and Drazin 1961; Dickinson 1968; Schoeberl 1978), but on rare occasions, also takes place at times when the polar vortex is fully developed-is the generally accepted cause of occasional wintertime circulation changes in the upper stratosphere and mesosphere. Accompanied by very large temperature anomalies (Scherhag 1952), which are attributed to adiabatic compression in descending air near where a low-latitude, low-PV streamer gains ground against the high-PV polar vortex, these events have historically been referred to as sudden stratospheric warmings. The commonly used criterion for socalled major warmings is that the zonally averaged 10hPa zonal wind at $60^{\circ} \mathrm{N}\left(\bar{u}_{60}\right)$ changes from westerly to easterly (e.g., Tripathi et al. 2016), a result of the intrusion of low-PV air into the polar region.

There is evidence (e.g., Shaw and Perlwitz 2013) that an SSW, while initiated by a vertically propagating planetary wave, renders the upper stratosphere more reflective to subsequent upward-propagating waves, thereby possibly affecting the tropospheric circulation in the days following the warming. Hence, SSWs are deemed relevant for subseasonal prediction.

We quantitatively assess SSW prediction skill in terms of the ACC [defined as (1) above] of predicted $\bar{u}_{60}$ for

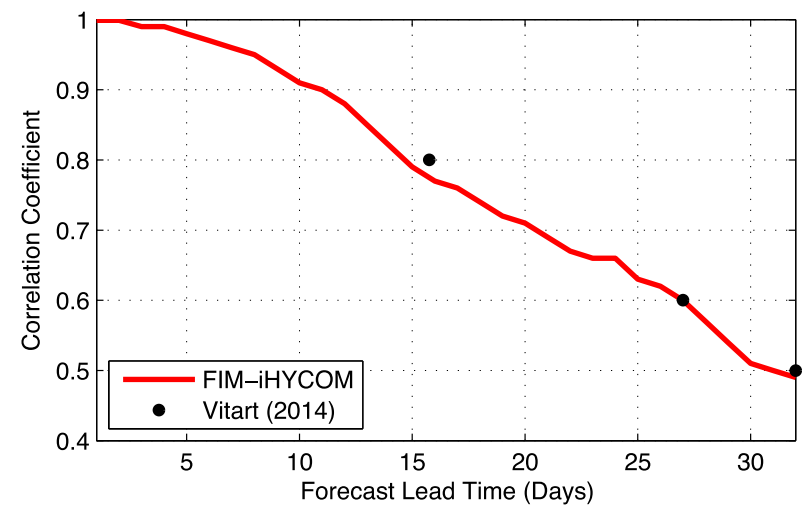

FIG. 14. ACCs of $\bar{u}_{60}$ predictions from FIM-iHYCOM for months October-March in years 1999/2000 to 2013/14, plotted against forecast lead time (days). Circles show ACC values for 2011 reproduced from Fig. 10 of Vitart (2014).

various lead times. Results from FIM-iHYCOM simulations initialized in the months October-March during the 16-yr hindcast period are shown in Fig. 14. The model skill is comparable to the ECMWF EPS forecast skill shown for the year 2011 in Fig. 10 of Vitart (2014), which is added in Fig. 14 for easier comparison.

Other models (Fig. 4 in Tripathi et al. 2016) show skill in predicting SSW for a key case in January 2013 up to 15 days in advance. Figure 15 illustrates the occurrence and predictive skill of SSW for two representative boreal winters (2008/09 and 2012/13) in FIM-iHYCOM simulations in terms of the maximum temperature on the 10-hPa surface $\left(T_{\max }\right)$ inside the polar cap north of $60^{\circ} \mathrm{N}$, as well as $\bar{u}_{60}$. The axes in the diagrams are model initialization time and forecast lead time (0-32 days). Lines of equal forecast verification time (dot-dashed in the figure) slope from upper left to lower right. To arrive at coherent contour plots despite the large data gap ( 1 week) on the abscissa, additional data points were created by linear interpolation in the oblique direction marked by the dot-dashed lines. Successfully predicted SSW events are depicted in this reference frame by $\bar{u}_{60}$ and $T_{\max }$ isopleths that are aligned with the dot-dashed lines.

Figure 15 shows that FIM-iHYCOM succeeds in predicting the SSWs in the 2 selected years up to 3 weeks in advance. However, the gradual loss of "slope" of the $\bar{u}_{60}$ isopleths illustrates a general tendency of FIM-iHYCOM to be late in predicting flow reversal at lead times beyond 10 days.

\section{Discussion}

The main goal of this study is to validate the new FIM-iHYCOM coupled model and generate a baseline for a systematic assessment of prediction skill with a 




$10 \mathrm{mb}$ zonally avg'd zonal velocity at $60 \mathrm{~N}$ fimG7

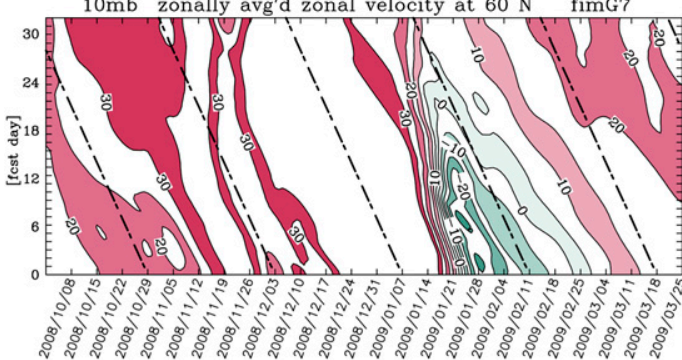

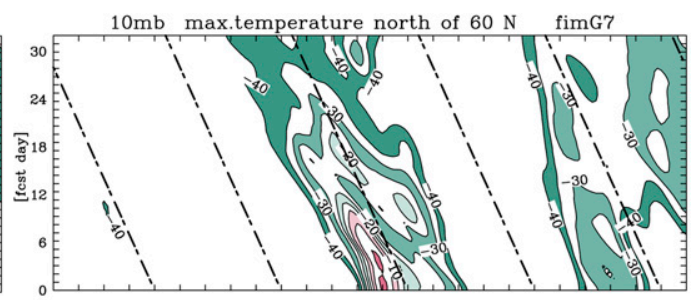

$10 \mathrm{mb}$ zonally avg'd zonal velocity at $60 \mathrm{~N}$ fimG7

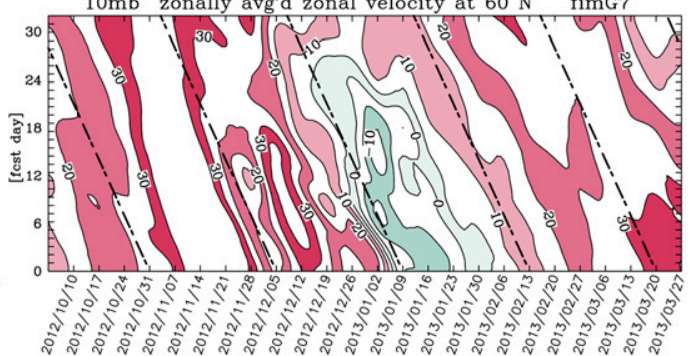

FIG. 15. Illustration of FIM-iHYCOM predictions for boreal winters (left) 2008/09 and (right) 2012/13. (top) Maximum 10-hPa temperature in polar cap north of $60^{\circ} \mathrm{N}\left({ }^{\circ} \mathrm{C}\right)$, and (bottom) $\bar{u}_{60}\left(\mathrm{~m} \mathrm{~s}^{-1}\right)$. Abscissa: model initialization time. Ordinate: forecast lead time (0-32 days). Slanted dot-dashed lines are lines of equal model verification time.

focus on subseasonal time scales, as an attempt to bridge the skill gap between weather forecasting and seasonal prediction. This is the second of two articles on subseasonal prediction with the new coupled modeling system, focusing on the model's probabilistic and deterministic prediction skill. Part I provided a detailed description of the coupled model, along with an evaluation of systematic seasonal biases.

A comprehensive hindcast dataset at $60-\mathrm{km}$ horizontal resolution was constructed by running a fourmember time-lagged ensemble on a weekly basis for the 16-yr period 1999-2014. The main focus is on the verification of $2-\mathrm{m}$ temperature, precipitation, and 500-hPa geopotential height, but we also attempt to shed light on the coupled model's ability to predict specific processes deemed relevant for longer-range prediction: namely, blocking, the Madden-Julian oscillation, and sudden stratospheric warming events. There is also a cursory comparison between model-simulated variability and that of observations. In subject areas where we are able to compare FIM-iHYCOM to CFSv2 (and other models), we find that the skill is comparable.

We analyzed weekly mean forecasts on a $1^{\circ} \times 1^{\circ}$ horizontal grid after removing biases extracted from the model's own climatology, except in the case of probabilistic skill, where model bias is accounted for implicitly. Despite the existing model biases shown in Part I, the competitive probabilistic and deterministic skills of FIM-iHYCOM for $\mathrm{T} 2 \mathrm{~m}$, precipitation, and $\mathrm{H} 500$, as well as the ability of the model to simulate various phenomena (blocking, the MJO, and SSWs), appear to be similar to those of the operational models of CFSv2, EPS, GEPS, and POAMA mentioned earlier. In addition, we compared the blocking frequency simulated by FIM-iHYCOM using two different indices and confirmed that the $\mathrm{PH}$ index is meteorologically more relevant than the TM index, at least for the Pacific blocks.

Our work is based on only four ensemble members, and no stochastic forcing is applied during model integration. Despite these limitations, FIM-iHYCOM shows promising skill in many aspects of the metrics used here and suggests a likely positive contribution to NOAA's multimodel Subseasonal Experiment (SubX).

Because of the nonstandard spatial discretization of the model equations on the sphere and in the vertical direction, and the inclusion of a different scale-aware convection scheme [namely, a variant of Grell and Freitas (2014)], the primary purpose of FIM-iHYCOM will be to enrich genetic diversity in multimodel ensembles that are increasingly being used in predicting atmospheric circulation anomalies and associated weather phenomena on time scales beyond 2 weeks. To become a candidate for inclusion in multimodel ensembles, an individual model must be demonstrated to be state-of-the-art in terms of its ability to simulate atmospheric flow patterns and weather regime transitions relevant to subseasonal weather prediction; this is the primary goal of this article.

In our future work, we will use FIM-iHYCOM, as well as coupled models based on NOAA's Next Generation Global Prediction System (NGGPS), to conduct 
more detailed, process-based studies of some of the subseasonally relevant phenomena that were given brief attention in this article. We will also investigate subseasonal as well as longer-term phenomena not yet covered in this article, such as tropical cyclone frequency, the stratospheric quasi-biennial oscillation, and El Niño-Southern Oscillation.

The dataset generated during this study has been made available to the research community through NOAA's SubX project. Combined with other existing subseasonal datasets, SubX offers the potential to improve our understanding of the mechanisms that are crucial for subseasonal prediction. The multimodel dataset also serves as a benchmark against which future coupled models will be compared, including models incorporating NGGPS, which is based on finite-volume numerics on a cubedsphere grid (e.g., Putman and Lin 2007).

Acknowledgments. This project was supported by NOAA OAR funding for week 3-4 forecast improvement and the Earth System Prediction Capability program. Coauthors Sun, Green, and Bleck are also supported by funding from NOAA OAR Award NA17OAR4320101. We thank Dr. Nicolas Vigaud for his helpful suggestions on building the extended logistic regression model, as well as Drs. John Brown and George Kiladis for providing internal reviews. Dr. Kathy Pegion also gave useful feedback. Three anonymous reviewers provided extensive feedback on an earlier version of this work. The authors acknowledge the NOAA Research and Development High Performance Computing Program for providing computing and data storage resources that have been instrumental in generating the results reported in this article (http://rdhpcs.noaa.gov), as well as the Texas Advanced Computing Center (TACC) at The University of Texas at Austin (http://www.tacc.utexas.edu). CFSv2 and CFSR data were obtained from the National Centers for Environmental Information.

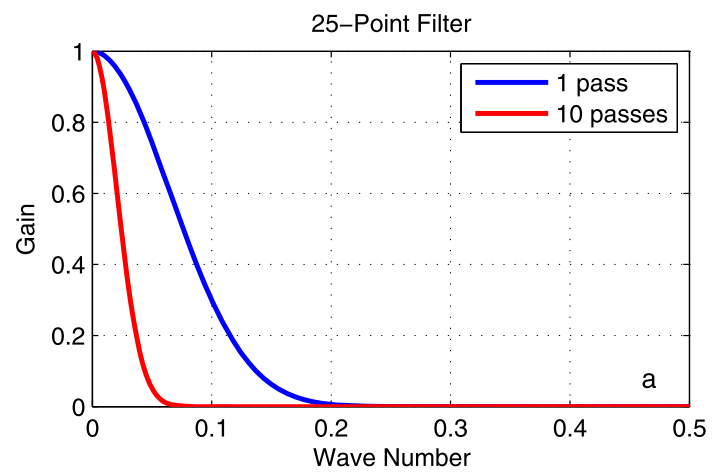

TABLE A1. Filter weights (starting with the central weight and progressing outward) of the symmetric 25 -point temporal and ninepoint spatial filters discussed in the appendix.

\begin{tabular}{ccc}
\hline \hline Point (from center) & 25-point filter & 9-point filter \\
\hline 1 & $1.611802578 \times 10^{-1}$ & $2.7343750 \times 10^{-1}$ \\
2 & $1.487817764 \times 10^{-1}$ & $2.1875000 \times 10^{-1}$ \\
3 & $1.168999672 \times 10^{-1}$ & $1.0937500 \times 10^{-1}$ \\
4 & $7.793331146 \times 10^{-2}$ & $3.1250000 \times 10^{-2}$ \\
5 & $4.383748770 \times 10^{-2}$ & $3.9062500 \times 10^{-3}$ \\
6 & $2.062940598 \times 10^{-2}$ & \\
7 & $8.022546768 \times 10^{-3}$ & \\
8 & $2.533435822 \times 10^{-3}$ & \\
9 & $6.333589554 \times 10^{-4}$ & \\
10 & $1.206398010 \times 10^{-4}$ & \\
11 & $1.645088196 \times 10^{-5}$ & \\
12 & $1.430511475 \times 10^{-6}$ & \\
13 & $5.960464478 \times 10^{-8}$ & \\
\hline
\end{tabular}

\section{APPENDIX}

\section{Low-Pass Filter Details}

A description of the procedure for generating a model-specific climatology would not be complete without documentation of the method used for eliminating short-term fluctuations from the raw model output. Here, we provide details of the low-pass filters employed in this work.

We use filters developed by Fleck and Fryer (1953) that offer advantages over both the use of running averages (which suffer from serious "ringing" throughout the frequency range) and the use of a finite number of Fourier components (which tends to suppress seasonal peaks). Fleck-Fryer filters have flawless damping characteristics at wavenumbers outside the low-pass window, a consequence of setting to zero as many derivatives as possible of the filter transfer function at the high-wavenumber end. The number of derivatives that can be specified increases with the number of filter weights.

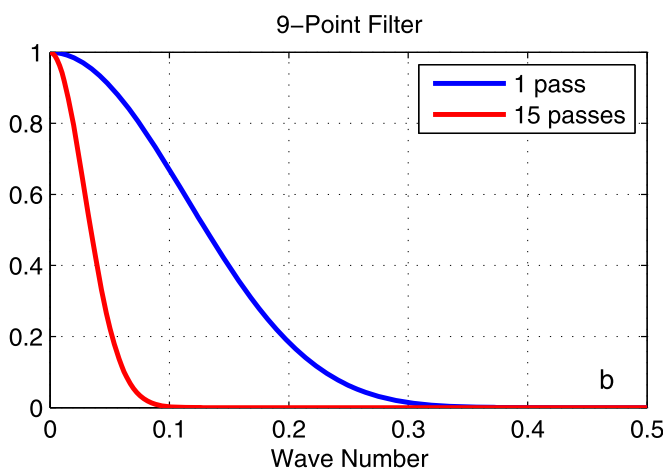

FIG. A1. Transfer functions for two low-pass filters used in this study. Red curves show the effect of applying the original filter (shown in blue) multiple times, as indicated. Abscissa: wavenumber in units of inverse data intervals. 
Starting with the center weight, the 13 independent weights for the 25-point time filter used in generating the model climatology are listed in the middle column of Table A1. (Note that filters must be symmetric with respect to the center weight to avoid phase shifts in the processed data.) The five independent weights of the nine-point longitudinal filter used in processing blocking statistics are listed in the right column of Table A1. The resulting transfer functions for these two filters used here are shown in Fig. A1.

\section{REFERENCES}

Baldwin, M. P., and T. J. Dunkerton, 1999: Propagation of the Arctic Oscillation from the stratosphere to the troposphere. J. Geophys. Res., 104, 30 937-30 946, https://doi.org/10.1029/ 1999JD900445.

Beljaars, A. C. M., P. Viterbo, M. J. Miller, and A. K. Betts, 1996: The anomalous rainfall over the United States during July 1993: Sensitivity to land surface parameterization and soil moisture anomalies. Mon. Wea. Rev., 124, 362-383, https://doi. org/10.1175/1520-0493(1996)124<0362:TAROTU>2.0.CO;2.

Bleck, R., 2002: An oceanic general circulation model framed in hybrid isopycnic-Cartesian coordinates. Ocean Modell., 4, 5588, https://doi.org/10.1016/S1463-5003(01)00012-9.

_ grid model for medium-range and seasonal prediction. Part I: Model description. Mon. Wea. Rev., 143, 2386-2403, https:// doi.org/10.1175/MWR-D-14-00300.1.

Brunet, G. N., and Coauthors, 2010: Collaboration of the weather and climate communities to advance subseasonal-to-seasonal prediction. Bull. Amer. Meteor. Soc., 91, 1397-1406, https:// doi.org/10.1175/2010BAMS3013.1.

Buizza, R., and M. Leutbecher, 2015: The forecast skill horizon. Quart. J. Roy. Meteor. Soc., 141, 3366-3382, https://doi.org/ 10.1002/qj.2619.

Charney, J. G., and P. G. Drazin, 1961: Propagation of planetary-scale disturbances from the lower into the upper atmosphere. J. Geophys. Res., 66, 83-109, https://doi.org/ 10.1029/JZ066i001p00083.

- - , and J. Shukla, 1981: Predictability of monsoons. Monsoon Dynamics, J. Lighthill and R. P. Pearce, Eds., Cambridge University Press, 99-110, https://doi.org/10.1017/ CBO9780511897580.009.

DelSole, T., L. Trenary, M. K. Tippett, and K. Pegion, 2017: Predictability of week-3-4 average temperature and precipitation over the contiguous United States. J. Climate, 30, 3499-3512, https://doi.org/10.1175/JCLI-D-16-0567.1.

Dickinson, R. E., 1968: Planetary Rossby waves propagating vertically through weak westerly wind wave guides. J. Atmos. Sci., 25, 984-1002, https://doi.org/10.1175/1520-0469(1968) 025<0984:PRWPVT>2.0.CO 2 .

Fleck, J. T., and W. D. Fryer, 1953: An exploration of numerical filtering techniques. Cornell Aeronautical Lab., Inc., Rep. XA-869-P-1, 79 pp.

Flierl, G. R., V. D. Larichev, J. C. McWilliams, and G. M. Reznik, 1980: The dynamics of baroclinic and barotropic solitary eddies. Dyn. Atmos. Oceans, 5, 1-41, https://doi.org/10.1016/ 0377-0265(80)90009-3.

Fortin, V., M. Abaza, F. Anctil, and R. Turcotte, 2014: Why should ensemble spread match the RMSE of the ensemble mean?
J. Hydrometeor., 15, 1708-1713, https://doi.org/10.1175/JHMD-14-0008.1.

Green, B. W., S. Sun, R. Bleck, S. G. Benjamin, and G. A. Grell, 2017: Evaluation of MJO predictive skill in multiphysics and multimodel global ensembles. Mon. Wea. Rev., 145, 25552574, https://doi.org/10.1175/MWR-D-16-0419.1.

Grell, G. A., and S. R. Freitas, 2014: A scale and aerosol aware stochastic convective parameterization for weather and air quality modeling. Atmos. Chem. Phys., 14, 5233-5250, https:// doi.org/10.5194/acp-14-5233-2014.

Hamill, T. M., and G. N. Kiladis, 2014: Skill of the MJO and Northern Hemisphere blocking in GEFS medium-range reforecasts. Mon. Wea. Rev., 142, 868-885, https://doi.org/ 10.1175/MWR-D-13-00199.1.

Han, J., and H.-L. Pan, 2011: Revision of convection and vertical diffusion schemes in the NCEP Global Forecast System. Wea. Forecasting, 26, 520-533, https://doi.org/10.1175/WAF-D-10-05038.1.

Hoerling, M. P., and A. Kumar, 2002: Atmospheric response patterns associated with tropical forcing. J. Climate, 15, 2184-2203, https://doi.org/10.1175/1520-0442(2002)015<2184: ARPAWT $>2.0 . \mathrm{CO} ; 2$.

Huffman, G. J., R. F. Adler, M. M. Morrissey, D. T. Bolvin, S. Curtis, R. Joyce, B. McGavock, and J. Susskind, 2001: Global precipitation at one-degree daily resolution from multisatellite observations. J. Hydrometeor., 2, 36-50, https://doi.org/10.1175/ 1525-7541(2001)002<0036:GPAODD>2.0.CO;2.

Jung, T., and Coauthors, 2012: High-resolution global climate simulations with the ECMWF model in Project Athena: Experimental design, model climate, and seasonal forecast skill. J. Climate, 25, 3155-3172, https://doi.org/10.1175/JCLI-D-11-00265.1.

Kalnay, E., and A. Dalcher, 1987: Forecasting forecast skill. Mon. Wea. Rev., 115, 349-356, https://doi.org/10.1175/1520-0493 (1987) $115<0349$ :FFS $>2.0$.CO;2.

— and Coauthors, 1996: The NCEP/NCAR 40-Year Reanalysis Project. Bull. Amer. Meteor. Soc., 77, 437-472, https://doi.org/ 10.1175/1520-0477(1996)077<0437:TNYRP>2.0.CO;2.

Kharin, V. V., and F. W. Zwiers, 2003: Improved seasonal probability forecasts. J. Climate, 16, 1684-1701, https://doi.org/ 10.1175/1520-0442(2003)016<1684:ISPF > 2.0.CO;2.

Kim, H.-M., P. J. Webster, V. E. Toma, and D. Kim, 2014: Predictability and prediction skill of the MJO in two operational forecasting systems. J. Climate, 27, 5364-5378, https://doi.org/ 10.1175/JCLI-D-13-00480.1.

Kirtman, B. P., and Coauthors, 2014: The North American Multimodel Ensemble: Phase-1 seasonal-to-interannual prediction; Phase-2 toward developing intraseasonal prediction. Bull. Amer. Meteor. Soc., 95, 585-601, https://doi.org/10.1175/ BAMS-D-12-00050.1.

Krishnamurti, T. N., and Coauthors, 2003: Improved skill for the anomaly correlation of geopotential heights at $500 \mathrm{hPa}$. Mon. Wea. Rev., 131, 1082-1102, https://doi.org/10.1175/15200493(2003)131<1082:ISFTAC > 2.0.CO;2.

Li, S., and A. W. Robertson, 2015: Evaluation of submonthly precipitation forecast skill from global ensemble prediction systems. Mon. Wea. Rev., 143, 2871-2889, https://doi.org/ 10.1175/MWR-D-14-00277.1.

Lin, H., N. Gagnon, S. Beauregard, R. Muncaster, M. Markovic, B. Denis, and M. Charron, 2016: GEPS-based monthly prediction at the Canadian Meteorological Centre. Mon. Wea. Rev., 144, 4867-4883, https://doi.org/10.1175/MWR-D-16-0138.1.

Lorenz, E. N., 1969: The predictability of a flow which possesses many scales of motion. Tellus, 21, 289-307, https://doi.org/ 10.3402/tellusa.v21i3.10086. 
Matsueda, M., 2011: Predictability of Euro-Russian blocking in summer of 2010. Geophys. Res. Lett., 38, L06801, https:// doi.org/10.1029/2010GL046557.

McIntyre, M. E., and T. N. Palmer, 1984: The 'surf zone' in the stratosphere. J. Atmos. Terr. Phys., 46, 825-849, https://doi. org/10.1016/0021-9169(84)90063-1.

Miyakoda, K., T. Gordon, R. Caverly, W. Stern, J. Sirutis, and W. Bourke, 1983: Simulation of a blocking event in January 1977. Mon. Wea. Rev., 111, 846-869, https://doi.org/10.1175/ 1520-0493(1983)111<0846:SOABEI > 2.0.CO;2.

NAS, 2016: Next Generation Earth System Prediction: Strategies for Subseasonal to Seasonal Forecasts. The National Academies Press, 350 pp., https://www.nap.edu/catalog/ 21873/next-generation-earth-system-prediction-strategiesfor-subseasonal-to-seasonal.

NOAA, 2017: S2S Prediction Task Force: Subseasonal to Seasonal (2016-2019). NOAA Climate Program Office, accessed 4 December 2017, https://cpo.noaa.gov/Meet-the-Divisions/ Earth-System-Science-and-Modeling/MAPP/MAPP-TaskForces/S2S-Prediction-Task-Force.

Palmer, T. N., 2002: The economic value of ensemble forecasts as a tool for risk assessment: From days to decades. Quart. J. Roy. Meteor. Soc., 128, 747-774, https://doi.org/10.1256/ 0035900021643593.

_ , and S. Tibaldi, 1988: On the prediction of forecast skill. Mon. Wea. Rev., 116, 2453-2480, https://doi.org/10.1175/1520-0493 (1988) $116<2453$ :OTPOFS $>2.0$. CO;2.

— model ensemble system for seasonal-to-interannual prediction (DEMETER). Bull. Amer. Meteor. Soc., 85, 853-872, https:// doi.org/10.1175/BAMS-85-6-853.

Pegion, K., and B. P. Kirtman, 2008: The impact of air-sea interactions on the simulation of tropical intraseasonal variability. J. Climate, 21, 6616-6635, https://doi.org/10.1175/ 2008JCLI2180.1.

Pelly, J. L., and B. J. Hoskins, 2003: A new perspective on blocking. J. Atmos. Sci., 60, 743-755, https://doi.org/10.1175/1520-0469 (2003)060<0743:ANPOB > 2.0.CO;2.

Putman, W. M., and S.-J. Lin, 2007: Finite-volume transport on various cubed-sphere grids. J. Comput. Phys., 227, 55-78, https://doi.org/10.1016/j.jcp.2007.07.022.

Rashid, H. A., H. H. Hendon, M. C. Wheeler, and O. Alves, 2011: Prediction of the Madden-Julian oscillation with the POAMA dynamical prediction system. Climate Dyn., 36, 649-661, https://doi.org/10.1007/s00382-010-0754-x.

Saha, S., and Coauthors, 2010: The NCEP Climate Forecast System Reanalysis. Bull. Amer. Meteor. Soc., 91, 1015-1058, https:// doi.org/10.1175/2010BAMS3001.1.

_- and Coauthors, 2014: The NCEP Climate Forecast System version 2. J. Climate, 27, 2185-2208, https://doi.org/10.1175/ JCLI-D-12-00823.1.

Scherhag, R., 1952: Die explosionsartigen Stratosphärenerwärmungen des Spätwinters 1951/1952. Ber. Dtsch. Wetterdienst. U.S. Zone, 38, 51-63.

Schoeberl, M. R., 1978: Stratospheric warmings: Observations and theory. Rev. Geophys., 16, 521-538, https://doi.org/10.1029/ RG016i004p00521.

Shaw, T. A., and J. Perlwitz, 2013: The life cycle of Northern Hemisphere downward wave coupling between the stratosphere and troposphere. J. Climate, 26, 1745-1763, https://doi. org/10.1175/JCLI-D-12-00251.1.

Smith, L. A., H. Du, E. B. Suckling, and F. Niehörster, 2015: Probabilistic skill in ensemble seasonal forecasts. Quart. J. Roy. Meteor. Soc., 141, 1085-1100, https://doi.org/10.1002/qj.2403.
Straus, D. M., and J. Shukla, 2000: Distinguishing between the SST-forced variability and internal variability in mid latitudes: Analysis of observations and GCM simulations. Quart. J. Roy. Meteor. Soc., 126, 2323-2350, https://doi.org/ 10.1256/smsqj.56715.

Sun, S., R. Bleck, S. G. Benjamin, B. W. Green, and G. A. Grell, 2018: Subseasonal forecasting with an icosahedral, vertically quasi-Lagrangian coupled model. Part I: Model overview and evaluation of systematic errors. Mon. Wea. Rev., 146, 1601-1617, https://doi.org/10.1175/MWRD-18-0006.1.

Tibaldi, S., and F. Molteni, 1990: On the operational predictability of blocking. Tellus, 42A, 343-365, https://doi.org/10.3402/ tellusa.v42i3.11882.

Tripathi, O. P., and Coauthors, 2016: Examining the predictability of the stratospheric sudden warming of January 2013 using multiple NWP systems. Mon. Wea. Rev., 144, 1935-1960, https://doi.org/10.1175/MWR-D-15-0010.1.

van den Dool, H. M., and Z. Toth, 1991: Why do forecasts for "near normal", often fail? Wea. Forecasting, 6, 76-85, https:// doi.org/10.1175/1520-0434(1991)006<0076:WDFFNO >2.0. $\mathrm{CO} ; 2$.

Ventrice, M. J., M. C. Wheeler, H. H. Hendon, C. J. Schreck III, C. D. Thorncroft, and G. N. Kiladis, 2013: A modified multivariate Madden-Julian oscillation index using velocity potential. Mon. Wea. Rev., 141, 4197-4210, https://doi.org/ 10.1175/MWR-D-12-00327.1.

Vigaud, N., A. W. Robertson, and M. K. Tippett, 2017: Multimodel ensembling of subseasonal precipitation forecasts over North America. Mon. Wea. Rev., 145, 3913-3928, https://doi.org/ 10.1175/MWR-D-17-0092.1.

Vitart, F., 2004: Monthly forecasting at ECMWF. Mon. Wea. Rev., 132, 2761-2779, https://doi.org/10.1175/MWR2826.1.

— 2014: Evolution of ECMWF sub-seasonal forecast skill scores. Quart. J. Roy. Meteor. Soc., 140, 1889-1899, https://doi. org/10.1002/qj.2256.

Waliser, D. E., K. M. Lau, W. Stern, and C. Jones, 2003: Potential predictability of the Madden-Julian oscillation. Bull. Amer. Meteor. Soc., 84, 33-50, https://doi.org/10.1175/ BAMS-84-1-33.

Walland, D. J., and I. Simmonds, 1996: Modelled atmospheric response to changes in Northern Hemisphere snow cover. Climate Dyn., 13, 25-34, https://doi.org/10.1007/ s003820050150.

Wang, W., M.-P. Hung, S. J. Weaver, A. Kumar, and X. Fu, 2014: MJO prediction in the NCEP Climate Forecast System version 2. Climate Dyn., 42, 2509-2520, https://doi.org/10.1007/ s00382-013-1806-9.

Wheeler, M. C., and H. H. Hendon, 2004: An all-season realtime multivariate MJO index: Development of an index for monitoring and prediction. Mon. Wea. Rev., 132, 19171932, https://doi.org/10.1175/1520-0493(2004)132<1917: AARMMI $>2.0 . \mathrm{CO} ; 2$.

—, H. Zhu, A. H. Sobel, D. Hudson, and F. Vitart, 2017: Seamless precipitation prediction skill comparison between two global models. Quart. J. Roy. Meteor. Soc., 143, 374-383, https://doi.org/10.1002/qj.2928.

Wilks, D. S., 2006: Statistical Methods in the Atmospheric Sciences. 2nd ed. International Geophysics Series, Vol. 100, Academic Press, 648 pp.

, 2009: Extending logistic regression to provide full-probabilitydistribution MOS forecasts. Meteor. Appl., 16, 361-368, https:// doi.org/10.1002/met.134. 
WMO, 2015: Seamless prediction of the Earth system: From minutes to months. WMO Tech. Rep. 1156, 483 pp., https://library. wmo.int/pmb_ged/wmo_1156_en.pdf.

Zhang, C., 2005: Madden-Julian oscillation. Rev. Geophys., 43, RG2003, https://doi.org/10.1029/2004RG000158.

,2013: Madden-Julian oscillation: Bridging weather and climate. Bull. Amer. Meteor. Soc., 94, 1849-1870, https://doi.org/ 10.1175/BAMS-D-12-00026.1.
Zhang, Q., and H. van den Dool, 2012: Relative merit of model improvement versus availability of retrospective forecasts: The case of Climate Forecast System MJO prediction. Wea. Forecasting, 27, 1045-1051, https://doi.org/10.1175/WAF-D-11-00133.1.

Zhu, H., M. C. Wheeler, A. H. Sobel, and D. Hudson, 2014: Seamless precipitation prediction skill in the tropics and extratropics from a global model. Mon. Wea. Rev., 142, 15561569, https://doi.org/10.1175/MWR-D-13-00222.1. 